\title{
Discovery and Structure-Activity Relationship Study of 4-Phenoxythiazol-5-carboxamides as Highly Potent TGR5 Agonists
}

\author{
Zhixiang Chen, ${ }^{a, b}$ Mengmeng Ning, ${ }^{b}$ Qingan Zou, ${ }^{b}$ Hua Cao, ${ }^{b}$ Yangliang Ye, ${ }^{* b}$ Ying Leng, ${ }^{*, b}$ and \\ Jianhua Shen ${ }^{b}$ \\ ${ }^{a}$ College of Pharmacy, Nanchang University; Nanchang 330006, China: and ${ }^{b}$ State Key Laboratory of Drug \\ Research, Shanghai Institute of Materia Medica (SIMM), Chinese Academy of Sciences; Shanghai 201203, China. \\ Received November 14, 2015; accepted January 14, 2016; advance publication released online February 4, 2016
}

\begin{abstract}
A novel therapy that stimulates endogenous glucagon-like peptide-1 (GLP-1) secretion by Takeda G-protein-coupled receptor 5 (TGR5) agonists might be a superior alternative for the treatment of type 2 diabetes mellitus. A series of 4-phenoxythiazol-5-carboxamides were developed as highly potent TGR5 agonists using a bioisosteric replacement strategy based on the scaffold of 4-phenoxynicotinamides. The structure-activity relationship on the bottom phenyl ring and the thiazole ring was extensively studied, and the 2-methylthiazole derivatives 30c and e displayed the best in vitro potency toward human TGR5, with $\mathbf{E C}_{50}$ values of approximately $1 \mathrm{nM}$. While endowed with excellent in vitro potency, the 2-methyl-thiazoles were flawed with high microsomal clearance.
\end{abstract}

Key words Takeda G-protein-coupled receptor 5 agonist; bioisostere; microsomal clearance; structureactivity relationship

Takeda G-protein-coupled receptor 5 (TGR5), also known as G-protein coupled bile acid receptor 1 (GPBAR1), is a cell surface receptor responsive to bile acids. It has been found to be ubiquitously expressed in animal and human tissues, including the liver, intestine, heart, spleen, skeletal muscle, brown adipose tissue, gallbladder and brain. ${ }^{1-4)}$ It is thought to play an important role in the regulation of energy homeostasis and glucose metabolism. Activation of the TGR5 receptor by bile acids triggers an increase in energy expenditure in brown adipose tissue and skeletal muscle. ${ }^{5)}$ More importantly, TGR5 activation also promotes glucagon-like peptide-1 (GLP-1) secretion in the intestine. ${ }^{6}$ ) As a member of the incretin family, GLP-1 acts as an important physiological regulator in glucose control via several mechanisms of action.7) But endogenous GLP-1 is significantly limited as a direct drug for the treatment of type 2 diabetes because of its rapid inactivation in plasma by dipeptidyl peptidase-4 (DPP-4). There are two main classes of alternative GLP-1-based drugs being widely used in a clinical setting: DPP-4 inhibitors and DPP-4-resistant GLP-1 receptor (GLP-1R) agonists. ${ }^{8)}$ However, these drugs may not be able to halt the progression of type 2 diabetes because they all exert their actions through increasing the plasma concentration of "GLP-1R agonists," and they thus may lack some of the local actions that endogenous GLP-1 is likely to have." Therefore, a novel therapy that stimulates endogenous GLP-1 secretion by TGR5 agonists is considered as a superior alternative for the treatment of type 2 diabetes mellitus.

In recent years, many different kinds of TGR5 agonists have been reported (Fig. 1). Structurally, TGR5 agonists can fall into two categories. The first category is bile acid derivatives, ${ }^{10-12)}$ such as lithocholic acid (LCA) and $6 \alpha$-ethyl-23(S)methylcholic acid (INT-777). The second category is non-bile acid derivatives, including naturally occurring non-bile acid agonists such as oleanolic acid and betulinic acid, ${ }^{13,14)}$ and synthetic small molecular TGR5 agonists. ${ }^{15-22)}$ However, only one compound (SB-756050) has ever been advanced into the clinical trial phase, and most are still in the discovery phase, because of a lack of appropriate Pharmacokinetic/Pharmacodynamic (PK/PD) profiles, or having side effects such as stimulating filling of the gallbladder, ${ }^{22,23)}$ or causing changes in heart rate and blood pressure. ${ }^{18)}$ Therefore, the search for a greater variety of promising TGR5 agonists with potent in vitro activity to expand the chemical library of TGR5 agonists still represents a very urgent need, and further optimizations based on such agonists could increase the possibility of producing drug candidates with good in vivo potency and low side-effects.

In our initial efforts to find novel TGR5 agonists, a scaffold of 4-phenoxynicotinamide (Fig. 2, scaffold A) was developed. ${ }^{22)}$ Using this scaffold as a basis, most of our previous structural explorations were focused on the upper tetrahydroquinoxaline region and the bottom phenyl ring, ${ }^{22,24)}$ whereas few explorations were carried out at the central core part, which was previously thought of as a limited region to alter. For this work, we investigated whether these alterations at the central core part would generate additional potent TGR5 agonists for further studies. First, we compared scaffold A with the scaffolds of other reported small molecular TGR5 agonists, and observed that scaffold $\mathbf{A}$ was very similar to the scaffolds of 5-8, with a five or six-membered heteroaromatic ring as a core part, one phenyl ring or heteroaromatic ring linked to the core via an amide bond, and another phenyl ring linked to the core directly or via oxygen. We therefore hypothesized that replacing the pyridine of scaffold $\mathbf{A}$ with five-membered heteroaromatic rings using a bioisosteric replacement strategy was likely to yield other TGR5 agonists with equivalent or even better potency (Fig. 2). To explore other scaffold that met our requirement, pyrazoles, 1,2,3-triazoles and 2-methyl-thiazoles were designed and synthesized. Herein, we describe our efforts in the synthesis, biological evaluations and structure-activity relationship (SAR) studies of this series of TGR5 agonists. 


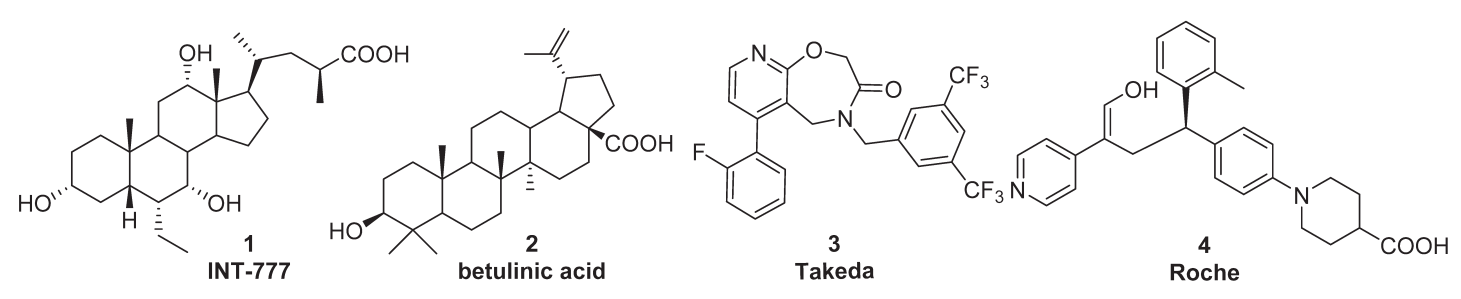<smiles>CCc1nnn2c1c(=O)n(-c1ccc(Cl)cc1)c1ccccc12</smiles><smiles>COc1ccc(S(=O)(=O)N2CCCN(S(=O)(=O)c3ccc(OC)c(OC)c3)CC2)cc1OC</smiles>

Fig. 1. Selected TGR5 Agonists Reported in the Literature and Patent
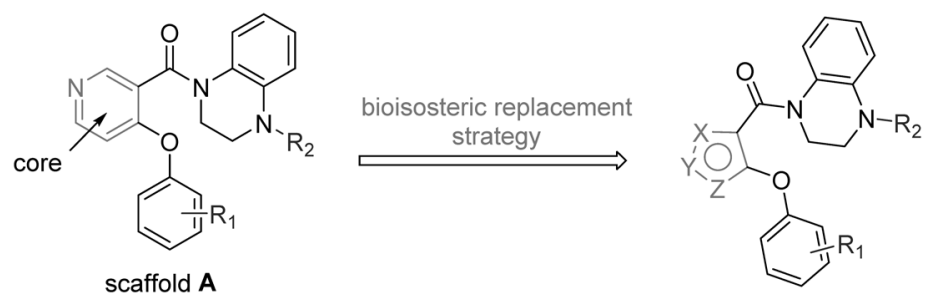

Fig. 2. Design of Other TGR5 Agonists for Further Studies Using a Bioisosteric Replacement Strategy
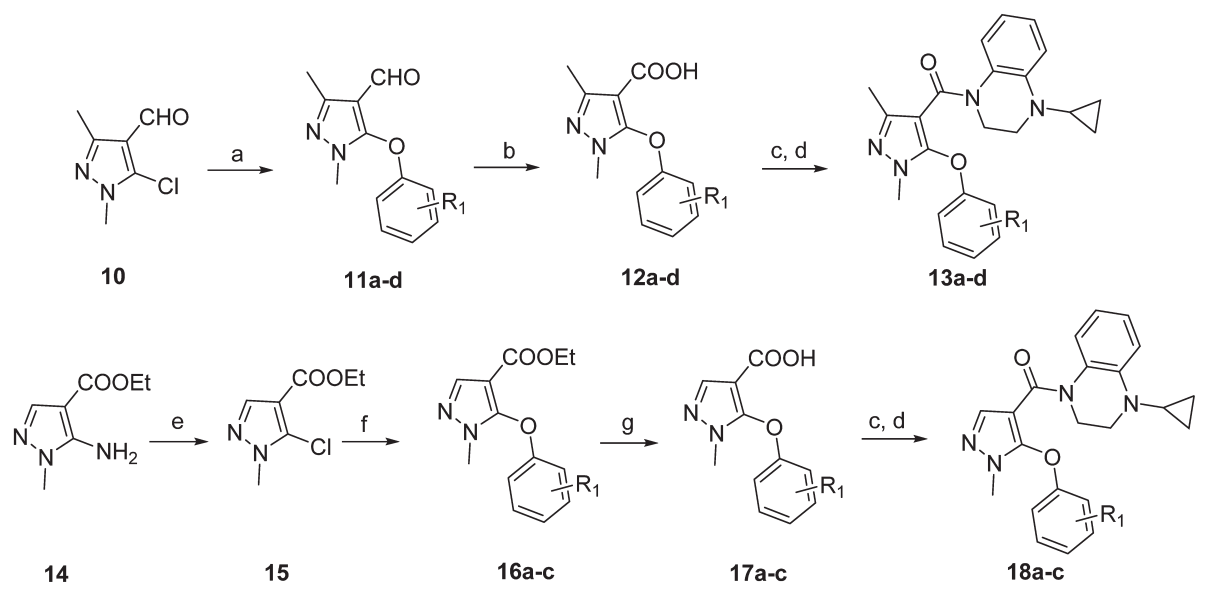

Reagents and conditions: (a) various substituted or unsubstituted phenols, $\mathrm{KOH}, \mathrm{DMF}, 100^{\circ} \mathrm{C}$; (b) $\mathrm{NaClO}_{2}, \mathrm{NaH}_{2} \mathrm{PO}_{4},{ }^{t} \mathrm{BuOH}, \mathrm{THF}, \mathrm{H}_{2} \mathrm{O}$; (c) $(\mathrm{COCl})_{2}, \mathrm{DMF}, \mathrm{DCM}$, reflux; (d) 1-cyclopropyl-1,2,3,4-tetrahydroquinoxaline, $\mathrm{Et}_{3} \mathrm{~N}$, DCM, r.t.; (e) $\mathrm{CuCl}_{2},{ }^{t} \mathrm{BuONO}^{\mathrm{MeCN}}, 60^{\circ} \mathrm{C}$; (f) various substituted or unsubstituted phenols, $\mathrm{K}_{2} \mathrm{CO}_{3}$, $\mathrm{DMF}$ $120^{\circ} \mathrm{C} ;(\mathrm{g}) \mathrm{NaOH}, 1,4$-dioxane, $\mathrm{H}_{2} \mathrm{O}$, r.t.

Chart 1. The Synthesis of Pyrazoles

\section{Chemistry}

The synthesis of pyrazole derivatives 13a-d and 18a-c are elucidated in Chart 1. Nucleophilic substitution on 3-chloropyrazole (10) with commercially available phenols afforded the aldehydes 11a-d, which were subsequent oxidized with sodium chlorite to give the key intermediates 12a-d. In contrast, 3-aminopyrazole (14) was transformed into a chlorine derivative (15) through diazotization in the presence of cupric chloride. Nucleophilic substitution with commercially available phenols and hydrolysis with sodium hydroxide generated the key intermediates $\mathbf{1 7 a}-\mathbf{c}$. Finally, the acids 12a-d and 17a-c were condensed with 1-cyclopropyl-1,2,3,4tetrahydroquinoxaline ${ }^{25)}$ to give the title compounds 13a-d and $18 \mathbf{a}-\mathbf{c}$.

The synthesis of 1,2,3-triazole derivatives is outlined in Chart 2. First, compound $\mathbf{1 9}$ was synthesized using a method described in the literature, ${ }^{26)}$ followed by treatment with phosphorus pentachloride, which yielded compound 20. ${ }^{27)}$ Next, the chlorine derivative $\mathbf{2 0}$ reacted with substituted phenols in the presence of sodium hydride to provide the diaryl ethers 21a-b. Through hydrolysis with sodium hydroxide and condensation with 1-cyclopropyl-1,2,3,4-tetrahydroquinoxaline or 1-methyl-1,2,3,4-tetrahydroquinoxaline, the key intermediates 23a and $\mathbf{b}$ and 24a and $\mathbf{b}$ were obtained. In addition, deprotection of compounds 24a and $\mathbf{b}$ gave the target compounds 25a and $\mathbf{b}$, whereas deprotection of compounds 23a and $\mathbf{b}$ was not 


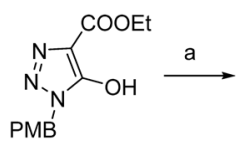

19

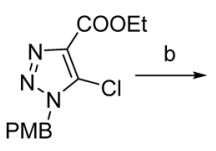

20

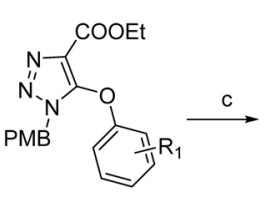

21a-b
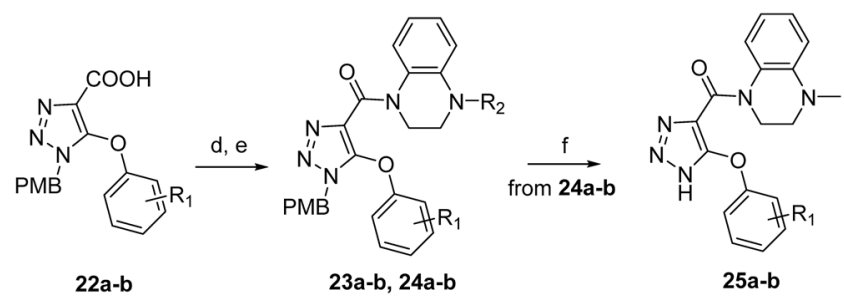

Reagents and conditions: (a) $\mathrm{PCl}_{5}$, toluene, $0^{\circ} \mathrm{C}$ to r.t.; (b) various substituted phenols, $\mathrm{NaH}, \mathrm{DMF}, 0$ to $85^{\circ} \mathrm{C}$; (c) $\mathrm{NaOH}, 1,4$-dioxane, $\mathrm{H}_{2} \mathrm{O}$, r.t.; (d) $(\mathrm{COCl})_{2}$, $\mathrm{DMF}, \mathrm{DCM}$, reflux; (e) 1-cyclopropyl-1,2,3,4-tetrahydroquinoxaline or 1-methyl-1,2,3,4-tetrahydroquinoxaline, $\mathrm{Et}_{3} \mathrm{~N}, \mathrm{DCM}$, r.t.; (f) TFA, $65^{\circ} \mathrm{C}$.

Chart 2. The Synthesis of 1,2,3-Triazoles

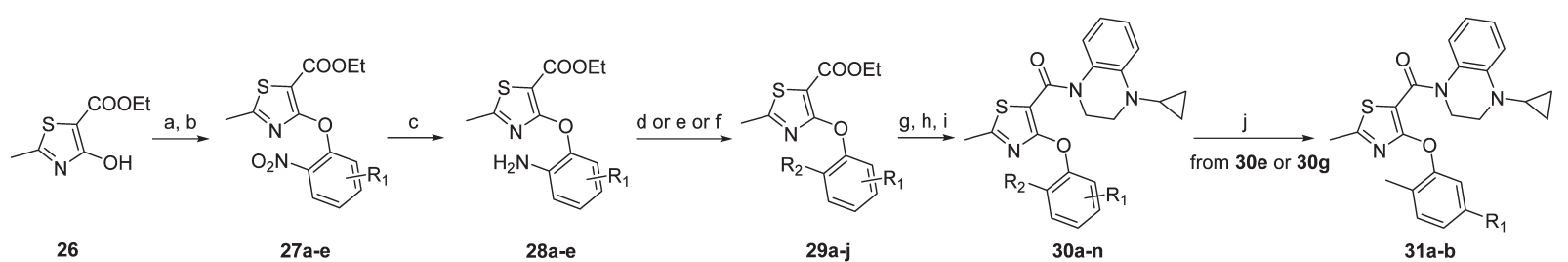

27a-e

28a-e

29a-j
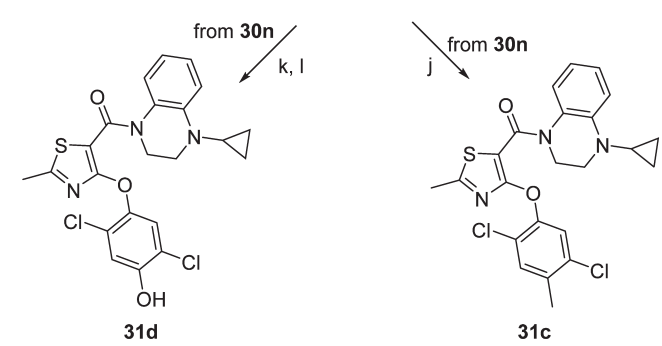

Reagents and conditions: (a) EtONa, EtOH; (b) substituted or unsubstituted $o$-fluoronitrobenzene, NMP, $\mathrm{Microwave} 125^{\circ} \mathrm{C}$; (c) $\mathrm{Fe}, \mathrm{NH}{ }_{4} \mathrm{Cl}, \mathrm{THF} \mathrm{H}_{2} \mathrm{O}$; (d) ${ }^{t} \mathrm{BuONO}$, $\mathrm{CuCl}_{2}, \mathrm{MeCN}$, r.t. $-60^{\circ} \mathrm{C}$; (e) ${ }^{t} \mathrm{BuONO}, \mathrm{CuBr}_{2}, \mathrm{MeCN}$, r.t. $-60^{\circ} \mathrm{C}$; (f) ${ }^{t} \mathrm{BuONO}, \mathrm{MeCN}$, reflux; (g) NaOH, 1,4-dioxane, H $\mathrm{H}_{2} \mathrm{O}$, r.t.; (h) $(\mathrm{COCl}){ }_{2}$, DMF, DCM, reflux; (i) 1-cyclopropyl-1,2,3,4-tetrahydroquinoxaline or 1-methyl-1,2,3,4-tetrahydroquinoxaline, $\mathrm{Et}_{3} \mathrm{~N}, \mathrm{DCM}$, r.t.; (j) $\mathrm{Zn}\left(\mathrm{CH}_{3}\right)_{2}, \mathrm{PdCl}_{2}(\mathrm{dppf}) \cdot \mathrm{CH}_{2} \mathrm{Cl}_{2}, 1,4-\mathrm{dioxane}, 80^{\circ} \mathrm{C} ;(\mathrm{k})$ $\mathrm{PdCl}_{2}$ (dppf) $\cdot \mathrm{CH}_{2} \mathrm{Cl}_{2}$, bis(pinacolato)diboron, KOAc, 1,4 -dioxane, $130^{\circ} \mathrm{C}$; (1) $\mathrm{H}_{2} \mathrm{O}_{2}$, THF, $0^{\circ} \mathrm{C}$-r.t.

Chart 3. The Synthesis of 2-Methyl-thiazoles

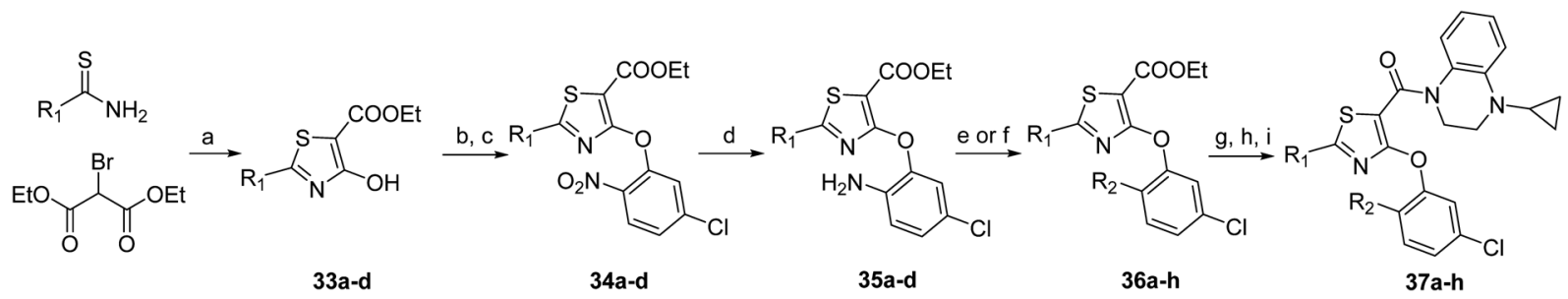

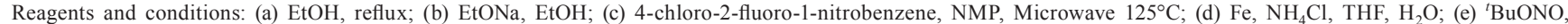
$\mathrm{CuCl}_{2}, \mathrm{MeCN}$, r.t. $-60^{\circ} \mathrm{C}$; (f) ${ }^{t} \mathrm{BuONO}, \mathrm{MeCN}$, reflux; (g) $\mathrm{NaOH}, 1,4$-dioxane, $\mathrm{H}_{2} \mathrm{O}$, r.t.; (h) (COCl), DMF, DCM, reflux; (i) 1-cyclopropyl-1,2,3,4-tetrahydroquinoxaline, $\mathrm{Et}_{3} \mathrm{~N}$, DCM, r.t.

Chart 4. The Synthesis of Thiazoles $\mathbf{3 7 a}-\mathbf{h}$

completed because of the unstable $N$-cyclopropyl group.

The synthesis of 2-methyl-thiazole derivatives is shown in Chart 3. This started with compound 26, which was prepared according to the procedure described in a patent, ${ }^{28)}$ followed by formation of a sodium salt and immediate treatment with various $o$-fluoronitrobenzenes under microwave assistance; this gave the key intermediates $\mathbf{2 7 a}-\mathbf{e}$. Next, reduction of the nitros $\mathbf{2 7} \mathbf{a}-\mathbf{e}$ to aminos $\mathbf{2 8 a}-\mathbf{e}$, and subsequent diazotization with tert-butyl nitrite in the presence of cupric chloride, cupric bromide or direct reflux, produced the intermediates 29a-j. Finally, via hydrolysis with sodium hydroxide and condensation as described above, the desired compounds 30a-n were obtained. Analogs $31 \mathbf{a}-\mathbf{c}$ were prepared from $\mathbf{3 0 e}, \mathbf{g}$ and $\mathbf{n}$ via the Negishi cross-coupling reaction. ${ }^{29)}$ Analog 31d was prepared through a $\mathrm{PdCl}_{2}(\mathrm{dppf}) \cdot \mathrm{CH}_{2} \mathrm{Cl}_{2}$-catalyzed reac- tion with bis(pinacolato)diboron and subsequent oxidation with hydrogen peroxide. In addition, direct hydrolysis of the intermediates 27a and $\mathbf{b}$ and subsequent condensation with 1-cyclopropyl-1,2,3,4-tetrahydroquinoxaline yielded 32a and b.

The synthesis of other thiazoles $\mathbf{3 7} \mathbf{a}-\mathbf{h}$ that were substituted with ethyl, isopropyl, phenyl or 2-pyridyl groups on the thiazole ring is show in Chart 4, which is similar to the protocols for preparation of 2-methyl-thiazole derivatives $30 \mathbf{c}$ and $\mathbf{i}$.

\section{Results and Discussion}

The newly-synthesized pyrazoles, 1,2,3-triazoles and 2-methyl-thiazoles were evaluated for their activity as agonists against human TGR5 (hTGR5) using a cAMP-responsive element (CRE)-driven luciferase assay in HEK293 cells. $^{22,24,30,31)}$ Compounds with $\mathrm{EC}_{50}$ values against hTGR5 of less than 
Table 1. In Vitro Activity of the Pyrazoles 13a-d and 18a-c

\begin{tabular}{|c|c|c|c|}
\hline Compound & $\mathrm{R}_{1}$ & $\mathrm{R}_{2}$ & hTGR5 $\left.\mathrm{EC}_{50}(\mathrm{nM})^{a}\right)$ \\
\hline $13 \mathbf{a}$ & $\mathrm{H}$ & $\mathrm{Me}$ & NA \\
\hline $13 b$ & 2,5-diCl & $\mathrm{Me}$ & NA \\
\hline $13 c$ & 2,5-diMe & $\mathrm{Me}$ & NA \\
\hline $13 d$ & 3-OMe & $\mathrm{Me}$ & NA \\
\hline $18 \mathrm{a}$ & $\mathrm{H}$ & $\mathrm{H}$ & NA \\
\hline $18 b$ & 2,5-diMe & $\mathrm{H}$ & NA \\
\hline $18 \mathrm{c}$ & 3-OMe & $\mathrm{H}$ & $129 \mathrm{~nm}$ \\
\hline
\end{tabular}

a) hTGR5 $\mathrm{EC}_{50}$ values given are the means of at least two independent experiments; NA: no measurable activity at a concentration of $0.1 \mu \mathrm{M}$ with two independent experiments.

Table 2. In Vitro Activity of the Triazoles 23a and b, 24a and $\mathbf{b}$ and 25a and $\mathbf{b}$

\begin{tabular}{|c|c|c|c|c|}
\hline Compound & $\mathrm{R}_{1}$ & $\mathrm{R}_{2}$ & $\mathrm{R}_{3}$ & hTGR5 effect ${ }^{a}$ \\
\hline $23 a$ & 2,5-diCl & $\mathrm{cPr}$ & PMB & NA \\
\hline 23b & 3-OMe & $\mathrm{cPr}$ & PMB & NA \\
\hline $24 a$ & 2,5-diCl & $\mathrm{Me}$ & PMB & NA \\
\hline $24 b$ & 3-OMe & $\mathrm{Me}$ & PMB & NA \\
\hline $25 a$ & 2,5-diCl & $\mathrm{Me}$ & $\mathrm{H}$ & NA \\
\hline $25 b$ & 3-OMe & $\mathrm{Me}$ & $\mathrm{H}$ & NA \\
\hline
\end{tabular}

a) NA: no measurable activity at a concentration of $0.1 \mu \mathrm{m}$ with two independent experiments.

$100 \mathrm{~nm}$ were then selected for the mouse TGR5 (mTGR5) activity test. The results are shown in Tables 1-3.

As shown in Table 1, the 5-methylpyrazoles were designed and prepared first. Compound 13a (with no substituent on the bottom phenyl ring) showed no measurable activity of hTGR5 at a concentration of $0.1 \mu \mathrm{M}$. Introduction of electron-withdrawing 2,5-dichloro (13b), electron-donating 2,5-dimethyl (13c) or 3-methoxyl (13d) group, also did not result in any promising activity. We hypothesized that the repulsive interaction between the methyl substituent on position 5 of pyrazole (compounds 13a-d) and the upper phenyl ring might cause a relatively great change of the spatial configuration between the upper phenyl ring and the middle core ring compared with scaffold A. Following removal of the 5-methyl substituent from the pyrazole ring, a series of 5-hydropyrazole derivatives $(\mathbf{1 8 a}-\mathbf{c})$ with similar substituents on the bottom phenyl ring were synthesized and evaluated in vitro. As anticipated, a great improvement in the in vitro potency was observed. Compound 18c with a 3-methoxyl substituent on the bottom phenyl ring exhibited moderate agonist activity, with a $\mathrm{hEC}_{50}$ value of $129 \mathrm{~nm}$. However, the in vitro potency of compound
Table 3. In Vitro Activity of the 2-Methyl-thiazoles 30a-m, 31a and $\mathbf{b}$ and 32a and $\mathbf{b}$

\begin{tabular}{|c|c|c|c|c|}
\hline Compound & $\mathrm{R}_{1}$ & $\mathrm{R}_{2}$ & $\underset{(\mathrm{nm})^{a)}}{\operatorname{hTGR5} \mathrm{EC}_{50}}$ & $\underset{(\mathrm{nm})^{b)}}{\operatorname{mTGR5~} \mathrm{EC}_{50}}$ \\
\hline INT-777 & - & - & $1226 \pm 357$ & $358 \pm 77$ \\
\hline 30a & 2-Cl-5-Me & $c \operatorname{Pr}$ & $1.4 \pm 0.22$ & $65 \pm 3.7$ \\
\hline $30 \mathrm{~b}$ & 2-Cl-5-Me & $\mathrm{Me}$ & $9.1 \pm 2.0$ & $484 \pm 87$ \\
\hline 30c & 2,5-diCl & $c \mathrm{Pr}$ & $1.1 \pm 0.07$ & $71 \pm 3.3$ \\
\hline 30d & 2,5-diCl & $\mathrm{Me}$ & $8.2 \pm 1.5$ & $563 \pm 29$ \\
\hline $30 \mathrm{e}$ & $2-\mathrm{Br}-5-\mathrm{Cl}$ & $c \operatorname{Pr}$ & $0.97 \pm 0.15$ & $72 \pm 15$ \\
\hline $30 \mathrm{f}$ & $2-\mathrm{Br}-5-\mathrm{Cl}$ & $\mathrm{Me}$ & $6.0 \pm 1.0$ & $499 \pm 35$ \\
\hline $30 \mathrm{~g}$ & 2-Br-5-Me & $c \operatorname{Pr}$ & $1.2 \pm 0.27$ & $67 \pm 4.8$ \\
\hline $30 \mathrm{~h}$ & 2-Br-5-Me & $\mathrm{Me}$ & $11 \pm 1.8$ & $479 \pm 80$ \\
\hline $31 \mathrm{a}$ & 5-Cl-2-Me & $c \operatorname{Pr}$ & $4.4 \pm 2.1$ & $141 \pm 0.28$ \\
\hline $31 \mathrm{~b}$ & 2,5-diMe & $c \mathrm{Pr}$ & $3.6 \pm 0.47$ & $100 \pm 50$ \\
\hline $32 a$ & $5-\mathrm{Cl}-2-\mathrm{NO}_{2}$ & $c \operatorname{Pr}$ & $7.6 \pm 0.16$ & $408 \pm 39$ \\
\hline $32 b$ & $5-\mathrm{Me}-2-\mathrm{NO}_{2}$ & $c \operatorname{Pr}$ & $7.5 \pm 2.0$ & $238 \pm 28$ \\
\hline $30 \mathrm{~m}$ & $2-\mathrm{Cl}$ & $c \operatorname{Pr}$ & $15 \pm 2.8$ & $227 \pm 31$ \\
\hline $30 \mathrm{i}$ & $3-\mathrm{Cl}$ & $c \operatorname{Pr}$ & $31 \pm 5.4$ & $931 \pm 90$ \\
\hline 301 & $4-\mathrm{Cl}$ & $c \operatorname{Pr}$ & $235 \pm 21$ & - \\
\hline $30 \mathrm{j}$ & 3-Me & $c \mathrm{Pr}$ & $26 \pm 6.1$ & $435 \pm 34$ \\
\hline $30 \mathrm{k}$ & 2,4-diCl & $c \operatorname{Pr}$ & $11 \pm 0.22$ & $331 \pm 68$ \\
\hline $30 n$ & 4-Br-2,5-diCl & $c \operatorname{Pr}$ & $2.8 \pm 0.42$ & $200 \pm 59$ \\
\hline $31 \mathrm{c}$ & 2,5-diCl-4-Me & $c \operatorname{Pr}$ & $1.5 \pm 0.40$ & $106 \pm 40$ \\
\hline 31d & 2,5-diCl-4-OH & $c \operatorname{Pr}$ & $1.4 \pm 0.31$ & $85 \pm 6.3$ \\
\hline
\end{tabular}

a) $\mathrm{EC}_{50}$ values of hTGR5 are expressed as the mean \pm S.D. of at least three independent experiments. $b$ ) $\mathrm{EC}_{50}$ values of mTGR5 are expressed as the mean \pm S.D. of at least two independent experiments.

18c was not sufficient for further studies, and as a result we discontinued exploration of the pyrazole scaffold.

The in vitro activity of 1,2,3-triazoles is shown in Table 2. It was disappointing that the intermediates 23a and $\mathbf{b}$ and 24a and $\mathbf{b}$ did not show any measureable activity at a concentration of $0.1 \mu \mathrm{M}$; neither did compounds $25 \mathbf{a}$ and $\mathbf{b}$. We speculated that the presence of a hydrogen bond donor at the triazole ring of compounds $\mathbf{2 5} \mathbf{a}$ and $\mathbf{b}$ might be extremely unfavorable for binding with the receptor, and the $p$-methoxybenzyl group on the triazole ring of compounds 23a and $\mathbf{b}$ and $24 \mathbf{a}$ and $\mathbf{b}$ was so large that it might result in a big change of the spatial configuration between the bottom phenyl ring and the middle triazole ring compared with the pyrazole derivative $\mathbf{1 8 c}$.

As shown in Table 3, the 2-methyl-thiazole series exhibited a dramatic improvement, especially for hTGR5 activity. To carry out preliminary screening of the 2-methyl-thiazole scaffold, the introductions of two substituents selected from a methyl, chloro or bromo moiety to the 2,5-di-positions of the bottom phenyl ring and a cyclopropyl or methyl group to the $R_{2}$ region gave the desired compounds $30 \mathbf{a}-\mathbf{h}$. Of these compounds, 30a, c, e and $\mathbf{g}$ were significantly more potent than the corresponding compounds with a methyl group in the $\mathrm{R}_{2}$ region, and all displayed extremely high potency toward hTGR5 in vitro, with $\mathrm{EC}_{50}$ values of approximately $1 \mathrm{~nm}$.

Next, we selected the $\mathrm{R}_{2}$ region with a cyclopropyl group into a subsequent library to further explore the SAR of the 
Table 4. In Vitro Activity and $C \log P$ Values of the Thiazoles $37 \mathbf{a}-\mathbf{h}$

\begin{tabular}{|c|c|c|c|c|}
\hline Compound & $\mathrm{R}_{1}$ & $\mathrm{R}_{2}$ & $\begin{array}{l}\text { hTGR5 } \mathrm{EC}_{50} \\
(\mathrm{nM})^{a)}\end{array}$ & $\begin{array}{c}\mathrm{mTGR}_{\left.(\mathrm{nM})^{b}\right)} \mathrm{EC}_{50} \\
\end{array}$ \\
\hline $30 \mathrm{c}$ & Methyl & $\mathrm{Cl}$ & $1.1 \pm 0.07$ & $71 \pm 3.3$ \\
\hline $37 \mathbf{a}$ & Ethyl & $\mathrm{Cl}$ & $32 \pm 6.2$ & $2137 \pm 317$ \\
\hline $37 \mathbf{b}$ & Ethyl & $\mathrm{H}$ & $185 \pm 74$ & - \\
\hline $37 \mathrm{c}$ & Isopropyl & $\mathrm{Cl}$ & $242 \pm 71$ & - \\
\hline $37 d$ & Isopropyl & $\mathrm{H}$ & $2817 \pm 110$ & - \\
\hline $37 \mathrm{e}$ & Phenyl & $\mathrm{Cl}$ & $6.9 \pm 2.3$ & $1865 \pm 252$ \\
\hline $37 f$ & Phenyl & $\mathrm{H}$ & $57 \pm 19$ & $>5000$ \\
\hline $37 \mathrm{~g}$ & 2-Pyridyl & $\mathrm{Cl}$ & $4.4 \pm 1.2$ & $746 \pm 7.0$ \\
\hline $37 \mathrm{~h}$ & 2-Pyridyl & $\mathrm{H}$ & $61 \pm 23$ & $>5000$ \\
\hline
\end{tabular}

a) $\mathrm{EC}_{50}$ values of hTGR5 and mTGR5 are expressed as the mean \pm S.D. of at least three independent experiments. $b$ ) $\mathrm{EC}_{50}$ values of hTGR5 and mTGR5 are expressed as the mean \pm S.D. of at least three independent experiments.

bottom phenyl region. Replacement of the 2-chloro of compounds 30a and $\mathbf{c}$ with a weak electron-donating methyl group (analogs 31a, b) led to a 3-4-fold decrease of the $\mathrm{hEC}_{50}$ and a slight decrease of the $\mathrm{mEC}_{50}$, and resulted in more reduction with an electron-withdrawing nitro group (compounds 32a, b). In addition, removal of the 2-chloro of compound 30a provided analog $\mathbf{3 0 j}$, which exhibited only moderate activity on hTGR5. Another key finding was that the in vitro activity of compounds $30 \mathbf{c}, \mathbf{i}, \mathbf{k}-\mathbf{m}$, which were substituted with a single chloro group or two chloro groups at different positions, followed the order $4-\mathrm{Cl} \ll 3-\mathrm{Cl}<2-\mathrm{Cl}<2,4-\mathrm{diCl} \ll 2,5-\mathrm{diCl}$, indicating that the 2,5-di-substitution was the best favored. Additionally, while keeping the 2,5-diCl groups intact, position 4 of compound 30c was also explored. It could be noted that various substitutions at position 4 of compound 30c were well tolerated, such as bromo (30n), methyl (31c) and hydroxyl (31d) substituents, which suggested that other groups might also be well tolerated. ${ }^{32}$ As a general rule, the 2-methylthiazole scaffold successfully maintained excellent in vitro potency.

To further explore the SAR of the thiazole ring, a series of thiazole derivatives that were substituted with ethyl, isopropyl, phenyl or 2-pyridyl groups on the thiazole ring were designed and synthesized (Table 4). Consistent with the observed SAR around the 2-methyl-thiazoles, the 2,5-dichloro analogs of these series were much better than the corresponding 3-dichloro analogs. Among the 2,5-dichloro analogs, compound 30c still displayed the best in vitro hTGR5 and mTGR5 potency. Interestingly, replacement of the methyl of compound 30c with ethyl (compound 37a) or isopropyl (compound 37c) resulted in a sharp decrease of potency on hTGR5, but only caused a slight loss with phenyl (compound 37e, $\mathrm{hEC}_{50}=6.9 \mathrm{nM}$ ) or 2-pyridyl (compound $37 \mathrm{~g}, \mathrm{hEC}_{50}=4.4 \mathrm{nM}$ ). To explain this result, the preferred conformations of compounds 30c, 37a, c, e and $\mathbf{g}$ were predicted in the software of ChemBio3D Ultra 14.0 using the MM2 algorithm. The methyl group of compound $30 \mathrm{c}$, the phenyl group of compound $37 \mathrm{e}$ and the 2-pyridyl group of compound $\mathbf{3 7} \mathbf{g}$ were observed at
Table 5. In Vitro Metabolic Stability of Representative Thiazoles

\begin{tabular}{|c|c|c|c|c|}
\hline Compound & $\mathrm{R}$ & Species & $T_{1 / 2}(\min )$ & $\begin{array}{c}C L_{\text {int }} \text { in vitro } \\
(\mathrm{mL} / \mathrm{min} / \mathrm{g})\end{array}$ \\
\hline \multirow[t]{2}{*}{$30 \mathbf{a}$} & \multirow[t]{2}{*}{ 2-Cl-5-Me } & Human & 1.1 & 1893 \\
\hline & & Mouse & 1.6 & 1297 \\
\hline \multirow[t]{2}{*}{$30 \mathrm{c}$} & \multirow[t]{2}{*}{ 2,5-diCl } & Human & 1.2 & 1698 \\
\hline & & Mouse & 2.7 & 780 \\
\hline \multirow[t]{2}{*}{$30 \mathrm{e}$} & \multirow[t]{2}{*}{ 2-Br-5-Cl } & Human & 1.4 & 1453 \\
\hline & & Mouse & 2.8 & 762 \\
\hline \multirow[t]{2}{*}{$30 \mathrm{~g}$} & \multirow[t]{2}{*}{ 2-Br-5-Me } & Human & 1.3 & 1678 \\
\hline & & Mouse & 2.2 & 959 \\
\hline \multirow[t]{2}{*}{$31 b$} & \multirow[t]{2}{*}{ 2,5-diMe } & Human & 1.0 & 2027 \\
\hline & & Mouse & 1.6 & 1341 \\
\hline \multirow[t]{2}{*}{$32 b$} & \multirow[t]{2}{*}{$5-\mathrm{Me}-2-\mathrm{NO}_{2}$} & Human & 1.2 & 1783 \\
\hline & & Mouse & 3.7 & 569 \\
\hline
\end{tabular}

the plane of thiazole ring, whereas part of the ethyl group of compound 37a and the isopropyl group of compound 37c were observed outside of the plane of thiazole ring. This observation suggested that the substitutions outside of the plane of the thiazole ring were not tolerated for high binding affinity, and which might disturb the postulated $\pi-\pi$ stacking interaction between the thiazole ring and the receptor of hTGR5. Due to the fact that the human TGR5 receptor shares only $83 \%$ amino acid identity with mouse TGR 5 receptor, ${ }^{10)}$ the in vitro activity of all thiazole derivatives on mTGR5 was significantly weaker than that on hTGR5. In general, in vitro activity of the 2-substituted-thiazole derivatives follow the order that methyl $>2$ pyridyl $>$ phenyl $>$ ethyl $>$ isopropyl.

Finally, given the fact that many reported small molecule TGR5 agonists were found with poor metabolic stability profile, which severely limited their further development as orally available agents, then some representative thiazoles were also selected to determine their metabolic clearance in human and mouse liver microsomes (MLM). Unfortunately, the select thiazoles all exhibited extremely high intrinsic clearance in both human liver microsome (HLM) and MLM (Table 5), especially for compound 31b (HLM $C L_{\text {int }}=2027 \mathrm{~mL} / \mathrm{min} / \mathrm{g}$, $T_{1 / 2}=1.0 \mathrm{~min} ; \quad$ MLM $\left.\quad C L_{\text {int }}=1341 \mathrm{~mL} / \mathrm{min} / \mathrm{g}, \quad T_{1 / 2}=1.6 \mathrm{~min}\right)$, which indicated that these compounds were deficient as tool compounds to investigate the therapeutic potential of systemic TGR5 agonists for the treatment of type 2 diabetes mellitus due to their high metabolic clearance.

\section{Conclusion}

In summary, a series of 4-phenoxythiazol-5-carboxamides were developed as highly potent TGR5 agonists using a bioisosteric replacement strategy based on scaffold $\mathbf{A}$, and extensive SAR explorations were described. Due to extremely high metabolic clearance, this series were insufficient as systemically targeted tool compounds. Considering that systemic TGR5 agonists that exposed to the gallbladder and heart were thought likely to result unfavorable side effects, and that 
making TGR5 agonists with low systemic exposure had the potential to minimize the side effects, our additional efforts are ongoing to determine if they can be used for intestinal targeting with limited systemic exposure combined with other medicinal chemistry strategies, such as introducing polar, hydrophilic groups to the position 4 of the bottom phenyl ring to reduce their absorption.

\section{Experimental}

In Vitro TGR5 Assay hTGR5/CRE/HEK293 or mTGR5/ CRE/HEK293 stable cell line was obtained by transfection of HEK293 cells with human or mouse TGR5 expression plasmid (hTGR5-pcDNA3.1 or mTGR5-pcDNA3.1) and CREdriven luciferase reporter plasmid (pGL4.29; Promega, Madison, WI, U.S.A.), and employed to assess the activity of test compounds by reporter gene assay. Briefly, cells were seeded into 96-well plates and incubated overnight in Dulbecco's modified Eagle's medium (DMEM) supplemented with 10\% fetal bovine serum (FBS) in $5 \% \mathrm{CO}_{2}$ at $37^{\circ} \mathrm{C}$. Then, cells were incubated with fresh medium containing different concentrations of test compounds or $20 \mu \mathrm{M}$ INT-777 as a positive control for $5.5 \mathrm{~h}$. Luciferase activity in cell lysate was determined using the Steady-Glo Luciferase Assay System (Promega) according to the manufacturer's instructions. Compounds with $\mathrm{EC}_{50}$ values on human TGR5 (hTGR5) less than $100 \mathrm{~nm}$ were selected for the mouse TGR5 (mTGR5) activity test.

In Vitro Microsomal Assay for Metabolic Stability The test compound was dissolved in dimethyl sulfoxide (DMSO) and diluted to the desired concentration with DMSO and $0.1 \%$ aqueous bovine serum albumin (BSA). Human or mouse liver microsomes were incubated in a 96-well plate containing $0.1 \mathrm{M}$ Tris buffer ( $\mathrm{pH} 7.4), 0.33 \mathrm{mg} / \mathrm{mL}$ microsomal protein, $0.1 \mu \mathrm{M}$ test compound, $5.0 \mathrm{~mm} \mathrm{MgCl}_{2}, 0.005 \% \mathrm{BSA}$, and $1.0 \mathrm{~mm}$ reduced nicotinamide adenine dinucleotide phosphate (NADPH). Incubations were conducted at $37^{\circ} \mathrm{C}$ for $60 \mathrm{~min}$. An aliquot was removed at each time point $(0,7,17,30$, $60 \mathrm{~min}$ ) and the enzymatic reaction was stopped by protein precipitation in methanol. The loss of the test compound was determined by LC-MS/MS. The intrinsic clearance $\left(C L_{\text {int }}, \mathrm{mL} /\right.$ $\mathrm{min} / \mathrm{g}$ microsomal protein) was calculated from the following equations.

$$
C=C_{0} \cdot \mathrm{e}^{(-k t)}
$$

$C_{0}$ : concentration at time $0 ; t$ : time $(\min ) ; k$ : slope $\left(\mathrm{min}^{-1}\right)$.

$$
C L_{\text {int }}=\frac{1000 \times \text { slope }}{P}
$$

$P$ : microsomal protein concentration $(\mathrm{mg} / \mathrm{mL})$.

Synthetic Materials and Methods Unless otherwise noted, all materials were purchased from commercial suppliers and used without further purification. All reaction yields were not optimized. Analytical TLC $(0.15-0.2 \mathrm{~mm})$ and preparative TLC $(0.4-0.5 \mathrm{~mm})$ were performed on $\mathrm{HSGF}_{254}$ (Yantai Jiangyou Company, Yantai, Shandong, China), compounds were visualized by UV light $(254 \mathrm{~nm})$. Column chromatography was carried out on silica gel (200-300 mesh) or with pre-packed silica cartridges (4-40g) from Bonna-Agela Technologies Inc. (Tianjin, China) and eluted with system of the Teledyne Isco CombiFlash $\mathrm{R}_{\mathrm{f}}$. Microwave reactions were performed in a Biatage Inititor. Melting point of target compounds was measured by SGWX-4 melting point apparatus (Shanghai Precision and Scientific Instrument Corporation, Shanghai, China). ${ }^{1} \mathrm{H}$ - and ${ }^{13} \mathrm{C}$-NMR spectra were recorded on a Bruker AC300 or a Bruker AC400 or a Bruker AC500 NMR spectrometer, using tetramethylsilane (TMS) as an internal reference. ${ }^{1} \mathrm{H}-\mathrm{NMR}$ date are reported as multiplicity (s singlet, d doublet, t triplet, q quarter, dd doublet of doublets, dt doublet of triplets, brs broad singlet, m multiplet), number of protons, and coupling constant in hertz (Hz). Spectra were carried in $\mathrm{CDCl}_{3}, \mathrm{DMSO}-d_{6}$, and $\mathrm{CD}_{3} \mathrm{OD}$. IR spectra were recorded on IS5 FT-IR (Thermo). Low-resolution mass spectra were determined on an Agilent LC-MS systems that consisted of an Agilent 1260 infinity LC coupled to an Agilent 6120 Quadrupole mass spectrometer (electrospray ionization $(\mathrm{ESI})+$ ) using an Agilent (Symmetry ${ }^{\circledR} \mathrm{C} 18$ Colum, $3.5 \mu \mathrm{m}$, $2.1 \times 50 \mathrm{~mm})$ with aqueous $\mathrm{CH}_{3} \mathrm{CN}(0.4 \mathrm{~mL} / \mathrm{min}, 0-5 \mathrm{~min}$, $30-90 \%$; 5-9 $\mathrm{min}, 90-90 \%$ ) containing $0.1 \%$ formic acid and monitored at $\lambda 240 \mathrm{~nm}$. High-resolution (HR) mass spectra were recorded on a Q-TOF Ultima Globe mass spectrameter (Micromass, Manchester, U.K.).

5-(2,5-Dimethylphenoxy)-1,3-dimethyl-1 H-pyrazole4-carbaldehyde (11c) Compound 10 (500 $\mathrm{mg}, 3.15 \mathrm{mmol})$ was dissolved in $N, N$-dimethylformamide (DMF) and treated with excess 2,5-dimethylphenol $(1.15 \mathrm{~g}, 9.43 \mathrm{mmol})$ and potassium hydroxide $(\mathrm{KOH})(270 \mathrm{mg}, 4,82 \mathrm{mmol})$, then the reaction mixture was stirred at $120^{\circ} \mathrm{C}$ for $2 \mathrm{~h}$. After consumption of 10 as monitored by TLC, the mixture was cooled to room temperature, then poured into water and extracted three times with EtOAc. The combined organic phases were washed with brine ( $3 \times)$, dried over $\mathrm{MgSO}_{4}$, filtered, and concentrated to dryness. The residue was purified by flash column chromatography to give 11c $(661 \mathrm{mg}, 86 \%) .{ }^{1} \mathrm{H}-\mathrm{NMR}\left(300 \mathrm{MHz}, \mathrm{CDCl}_{3}\right)$ $\delta: 9.33(1 \mathrm{H}, \mathrm{s}), 7.13(1 \mathrm{H}, \mathrm{d}, J=5.7 \mathrm{~Hz}), 6.89(1 \mathrm{H}, \mathrm{d}, J=5.7 \mathrm{~Hz}$,), $6.53(1 \mathrm{H}, \mathrm{s}), 3.64(3 \mathrm{H}, \mathrm{s}), 2.45(3 \mathrm{H}, \mathrm{s}), 2.32(3 \mathrm{H}, \mathrm{s}), 2.24(3 \mathrm{H}$, s).

5-(2,5-Dimethylphenoxy)-1,3-dimethyl-1 $H$-pyrazole4-carboxylic Acid (12c) To a solution of 11c (0.62 g, $2.54 \mathrm{mmol})$ in mixed of tertiary butanol $(9 \mathrm{~mL})$, tetrahydrofuran (THF) $(9 \mathrm{~mL})$ and $\mathrm{H}_{2} \mathrm{O}(3 \mathrm{~mL})$, was added $\mathrm{NaH}_{2} \mathrm{PO}_{4}$ $(1.83 \mathrm{~g}, 15.2 \mathrm{mmol}), \mathrm{NaClO}_{2}(1.38 \mathrm{~g}, 15.2 \mathrm{mmol})$ and 2-methylbut-2-ene $(4 \mathrm{~mL})$, and then allowed to stir at room temperature (r.t.) for $3 \mathrm{~h}$. After completion of the reaction, the solvent was removed by rotary evaporation, and the crude was suspended in water. The precipitate was collected via filtration to yield 12c $(0.60 \mathrm{~g}, 92 \%) .{ }^{1} \mathrm{H}-\mathrm{NMR}(300 \mathrm{MHz}, \mathrm{DMSO}) \delta$ : $12.01(1 \mathrm{H}$, br), $7.14(1 \mathrm{H}, \mathrm{d}, J=7.8 \mathrm{~Hz}), 6.80(1 \mathrm{H}, \mathrm{d}, J=7.8 \mathrm{~Hz}), 6.25(1 \mathrm{H}, \mathrm{s})$, $3.52(3 \mathrm{H}, \mathrm{s}), 2.32(3 \mathrm{H}, \mathrm{s}), 2.28(3 \mathrm{H}, \mathrm{s}), 2.16(3 \mathrm{H}, \mathrm{s})$.

(4-Cyclopropyl-3,4-dihydroquinoxalin-1(2H)-yl)(5-(2,5dimethylphenoxy)-1,3-dimethyl- $1 H$-pyrazol-4-yl)methanone (13c) To a solution of $12 \mathrm{c}(0.5 \mathrm{~g}, 1.92 \mathrm{mmol})$ in dry dichloromethane (DCM) was added oxalyl chloride $(491 \mu \mathrm{L}$, $5.76 \mathrm{mmol}$ ) and three drops DMF, and held at reflux for $2 \mathrm{~h}$. Then the reaction mixture was cooled to room temperature and concentrated. The residue was re-dissolved in dry DCM, 1-cyclopropyl-1,2,3,4-tetrahydroquinoxaline (341 mg, $1.92 \mathrm{mmol})$ and $\mathrm{Et}_{3} \mathrm{~N}(797 \mu \mathrm{L}, 5.76 \mathrm{mmol})$ were added, and the reaction was stirred at r.t. overnight. After completion, the reaction was diluted with water and extracted with DCM $(3 \times)$. The combined organic phases were collected, washed with brine, dried over $\mathrm{MgSO}_{4}$, concentrated and purified by 
flash column chromatography to afford the title compound 13c $(624 \mathrm{mg})$ as an off-white solid in $78 \%$ yield. $\mathrm{mp} 124^{\circ} \mathrm{C}$. ${ }^{1} \mathrm{H}-\mathrm{NMR} \quad\left(300 \mathrm{MHz}, \quad \mathrm{CDCl}_{3}\right) \quad \delta: 7.07 \quad(1 \mathrm{H}, \quad \mathrm{dd}, \quad J=0.9 \mathrm{~Hz}$, $6.3 \mathrm{~Hz}), 6.99-6.94(2 \mathrm{H}, \mathrm{m}), 6.75(2 \mathrm{H}, \mathrm{d}, J=5.7 \mathrm{~Hz}), 6.49(1 \mathrm{H}$, dt, $J=0.9,6.0 \mathrm{~Hz}), 6.40(1 \mathrm{H}, \mathrm{s}), 3.73(2 \mathrm{H}, \mathrm{m}), 3.49(3 \mathrm{H}, \mathrm{s}), 2.91$ $(2 \mathrm{H}, \mathrm{m}), 2.30(1 \mathrm{H}, \mathrm{m}), 2.26(3 \mathrm{H}, \mathrm{s}), 2.20(3 \mathrm{H}, \mathrm{s}), 2.01(3 \mathrm{H}, \mathrm{s})$, $0.74(2 \mathrm{H}, \mathrm{m}), 0.45(2 \mathrm{H}, \mathrm{m}) .{ }^{13} \mathrm{C}-\mathrm{NMR}\left(126 \mathrm{MHz}, \mathrm{CDCl}_{3}\right) \delta$ : $162.07,154.12,148.23,146.18,139.16,137.04,131.01,125.41$, $125.27,123.82,123.07,122.55,116.28,113.34,112.97,103.61$, $48.36,40.66,34.15,31.27,21.12,15.55,13.62,7.89$. IR (KBr) $\mathrm{cm}^{-1}: 1626.27,1504.57,1419.43,1404.60,1361.74,738.51$. HPLC-MS: $5.66 \mathrm{~min}, 417.3\left(\mathrm{M}+\mathrm{H}^{+}\right)$. HR-MS (ESI): $\mathrm{m} / \mathrm{z}$ $\left(\mathrm{M}+\mathrm{H}^{+}\right)$Calcd for $\mathrm{C}_{25} \mathrm{H}_{29} \mathrm{O}_{2} \mathrm{~N}_{4}: 417.2285$. Found: 417.2275.

(4-Cyclopropyl-3,4-dihydroquinoxalin-1(2H)-yl)(1,3dimethyl-5-phenoxy-1H-pyrazol-4-yl)methanone

(13a)

The title compound 13a was prepared from 10 and phenol according to a procedure similar to that described for the preparation of the title compound $13 \mathrm{c} . \mathrm{mp} 145^{\circ} \mathrm{C} .{ }^{1} \mathrm{H}-\mathrm{NMR}$ $\left(300 \mathrm{MHz}, \mathrm{CDCl}_{3}\right) \delta: 7.24(2 \mathrm{H}, \mathrm{t}, J=6.0 \mathrm{~Hz}), 7.13(1 \mathrm{H}, \mathrm{d}$, $J=5.7 \mathrm{~Hz}), 7.05(1 \mathrm{H}, \mathrm{d}, J=5.7 \mathrm{~Hz}), 7.00(1 \mathrm{H}, \mathrm{d}, J=6.3 \mathrm{~Hz})$, $6.73(2 \mathrm{H}, \mathrm{d}, J=6.0 \mathrm{~Hz}), 6.70(1 \mathrm{H}, \mathrm{d}, J=6.3 \mathrm{~Hz}), 6.48(1 \mathrm{H}$, t, $J=5.7 \mathrm{~Hz}), 3.72(2 \mathrm{H}, \mathrm{m}), 3.53(3 \mathrm{H}, \mathrm{s}), 2.85(2 \mathrm{H}, \mathrm{m}), 2.30$ $(1 \mathrm{H}, \mathrm{m}), 2.28(3 \mathrm{H}, \mathrm{s}), 0.78(2 \mathrm{H}, \mathrm{m}), 0.51(2 \mathrm{H}, \mathrm{m}) .{ }^{13} \mathrm{C}-\mathrm{NMR}$ $\left(126 \mathrm{MHz}, \mathrm{CDCl}_{3}\right) \delta: 161.89,156.36,148.53,145.96,139.18$, $129.77,125.41,125.24,123.45,122.64,116.24,115.04,112.76$, $103.29,48.25,40.50,34.20,31.25,13.61,7.99$. IR $(\mathrm{KBr}) \mathrm{cm}^{-1}$ : 1621.84, 1502.90, 1489.58, 1411.74, 1400.72, 1320.10, 756.37. HPLC-MS: $4.93 \mathrm{~min}, 389.3\left(\mathrm{M}+\mathrm{H}^{+}\right)$. HR-MS (ESI): $\mathrm{m} / \mathrm{z}$ $\left(\mathrm{M}+\mathrm{H}^{+}\right)$Calcd for $\mathrm{C}_{23} \mathrm{H}_{25} \mathrm{O}_{2} \mathrm{~N}_{4}: 389.1972$. Found: 389.1965 .

(4-Cyclopropyl-3,4-dihydroquinoxalin-1(2H)-yl)(5-(2,5dichlorophenoxy)-1,3-dimethyl-1 $H$-pyrazol-4-yl)methanone (13b) The title compound 13b was obtained as a white solid from 10 and 2,5-dichlorophenol according to the general procedure. mp $139^{\circ} \mathrm{C} .{ }^{1} \mathrm{H}-\mathrm{NMR}\left(300 \mathrm{MHz}, \mathrm{CDCl}_{3}\right) \delta: 7.15(1 \mathrm{H}, \mathrm{d}$, $J=7.8 \mathrm{~Hz}), 7.00(1 \mathrm{H}, \mathrm{dt}, J=1.2,7.8 \mathrm{~Hz}), 6.72(1 \mathrm{H}, \mathrm{d}, J=7.8 \mathrm{~Hz})$, $6.62(1 \mathrm{H}, \mathrm{d}, J=8.7 \mathrm{~Hz}), 6.49(1 \mathrm{H}, \mathrm{t}, J=7.8 \mathrm{~Hz}), 6.30(1 \mathrm{H}, \mathrm{d}$, $J=2.4 \mathrm{~Hz}), 6.18(1 \mathrm{H}, \mathrm{dd}, J=2.4,8.7 \mathrm{~Hz}), 3.76(2 \mathrm{H}, \mathrm{m}), 3.52$ $(3 \mathrm{H}, \mathrm{s}), 3.02(2 \mathrm{H}, \mathrm{m}), 2.35(1 \mathrm{H}, \mathrm{m}), 2.22(3 \mathrm{H}, \mathrm{s}), 0.80(2 \mathrm{H}, \mathrm{m})$, $0.55(2 \mathrm{H}, \mathrm{m}) .{ }^{13} \mathrm{C}-\mathrm{NMR}\left(126 \mathrm{MHz}, \mathrm{CDCl}_{3}\right) \delta: 165.04,161.57$, $156.72,151.78,148.00,145.43,139.52,133.40,131.21,125.81$, $124.49,122.84,120.85,116.53,116.00,113.19,48.91,41.19$, 34.49, 31.26, 13.44, 7.98. HPLC-MS: $5.76 \mathrm{~min}, 457.2\left(\mathrm{M}+\mathrm{H}^{+}\right)$. HR-MS (ESI): $m / z \quad\left(\mathrm{M}+\mathrm{H}^{+}\right)$Calcd for $\mathrm{C}_{23} \mathrm{H}_{23} \mathrm{O}_{2} \mathrm{~N}_{4} \mathrm{Cl}_{2}$ : 457.1193. Found: 457.1186.

(4-Cyclopropyl-3,4-dihydroquinoxalin-1(2H)-yl)(5-(3methoxyphenoxy)-1,3-dimethyl-1 $H$-pyrazol-4-yl)methanone (13d) The title compound 13d was prepared from $\mathbf{1 0}$ and 3-methoxyphenol following the general procedure. $\mathrm{mp}$ $109^{\circ} \mathrm{C} .{ }^{1} \mathrm{H}-\mathrm{NMR}\left(300 \mathrm{MHz}, \mathrm{CDCl}_{3}\right) \delta: 7.15(2 \mathrm{H}, \mathrm{m}), 6.99(1 \mathrm{H}$, t, $J=8.1 \mathrm{~Hz}), 6.71(1 \mathrm{H}, \mathrm{d}, J=7.5 \mathrm{~Hz}), 6.61(1 \mathrm{H}, \mathrm{m}), 6.48(1 \mathrm{H}$, $\mathrm{m}), 6.31(2 \mathrm{H}, \mathrm{m}), 3.77(2 \mathrm{H}, \mathrm{m}), 3.74(3 \mathrm{H}, \mathrm{s}), 3.52(3 \mathrm{H}, \mathrm{s}), 2.90$ $(2 \mathrm{H}, \mathrm{m}), 2.30(1 \mathrm{H}, \mathrm{m}), 2.25(3 \mathrm{H}, \mathrm{s}), 0.78(2 \mathrm{H}, \mathrm{m}), 0.50(2 \mathrm{H}, \mathrm{m})$. ${ }^{13} \mathrm{C}-\mathrm{NMR}\left(126 \mathrm{MHz}, \mathrm{CDCl}_{3}\right) \delta: 160.84,157.34,151.14,148.44$, $139.24,130.30,130.20,125.40,122.65,116.24,112.80,109.02$, $108.96,107.13,106.96,101.78,55.44,48.26,40.98,34.22$, 31.20, 22.70, 13.60, 7.99. HPLC-MS: $4.99 \mathrm{~min}, 419.3\left(\mathrm{M}+\mathrm{H}^{+}\right)$. HR-MS (ESI): $m / z\left(\mathrm{M}+\mathrm{H}^{+}\right)$Calcd for $\mathrm{C}_{24} \mathrm{H}_{27} \mathrm{O}_{3} \mathrm{~N}_{4}: 419.2078$. Found: 419.2072 .

Ethyl-5-chloro-1-methyl-1H-pyrazole-4-carboxylate (15) To a solution of ${ }^{t} \mathrm{BuONO}(2.95 \mathrm{~mL}, 2.46 \mathrm{mmol})$ in acetonitrile $(\mathrm{ACN})$ was added $\mathrm{CuCl}(1.76 \mathrm{~g}, 1.77 \mathrm{mmol})$, and then added
$14(2.5 \mathrm{~g}, 1.48 \mathrm{mmol})$ to the mixture in portions. The reaction was stirred at r.t. for $2 \mathrm{~h}$, and then heated at $60^{\circ} \mathrm{C}$ for $1 \mathrm{~h}$. After completion as TLC monitored, the reaction mixture was cooled to r.t. and diluted with $2 \mathrm{~N}$ aq. $\mathrm{HCl}$, then extracted with DCM $(3 \times)$. The combined phases were washed with brine, dried over $\mathrm{MgSO}_{4}$, filtered, concentrated and purified by flash column chromatography to give $15(2.08 \mathrm{~g})$ in $75 \%$ yield. ${ }^{1} \mathrm{H}-\mathrm{NMR}\left(300 \mathrm{MHz}, \mathrm{CDCl}_{3}\right) \delta: 7.90(1 \mathrm{H}, \mathrm{s}), 4.30(2 \mathrm{H}, \mathrm{q}$, $J=5.4 \mathrm{~Hz}), 3.86(3 \mathrm{H}, \mathrm{s}), 1.34(3 \mathrm{H}, \mathrm{t}, J=5.4 \mathrm{~Hz})$.

Ethyl-1-methyl-5-phenoxy-1 $\boldsymbol{H}$-pyrazole-4-carboxylate (16a) In a microwave reaction vessel was combined 15 (300 mg, $1.59 \mathrm{mmol}$ ), phenol $(300 \mathrm{mg}, 3.19 \mathrm{mmol})$ and $\mathrm{Cs}_{2} \mathrm{CO}_{3}$ $(1.52 \mathrm{~g}, 4.66 \mathrm{mmol})$ in DMF. The vessel was sealed and the resulting mixture was heated at $120^{\circ} \mathrm{C}$ by microwave for $30 \mathrm{~min}$. Then the reaction mixture was cooled to r.t., quenched with water and extracted with EtOAc three times. The organic layer was collected, washed with brine, dried over $\mathrm{MgSO}_{4}$ and filtered. After the solvent was removed, the crude was purified by flash column chromatography to yield $\mathbf{1 6 a}$ ( $280 \mathrm{mg}, 72 \%)$. ${ }^{1} \mathrm{H}-\mathrm{NMR}\left(300 \mathrm{MHz}, \mathrm{CDCl}_{3}\right) \delta: 7.92(1 \mathrm{H}, \mathrm{s}), 7.3(2 \mathrm{H}, \mathrm{dt}, J=2.1$, $7.2 \mathrm{~Hz}), 7.10(1 \mathrm{H}, \mathrm{dt}, J=1.2,7.2 \mathrm{~Hz}), 6.89(2 \mathrm{H}, \mathrm{m}), 4.07(2 \mathrm{H}, \mathrm{q}$, $J=7.2 \mathrm{~Hz}), 3.71(3 \mathrm{H}, \mathrm{s}), 1.03(3 \mathrm{H}, \mathrm{t}, J=7.2 \mathrm{~Hz})$.

1-Methyl-5-phenoxy-1H-pyrazole-4-carboxylic Acid (17a) 16a $(270 \mathrm{mg}, 1.10 \mathrm{mmol})$ was dissolved in a solution of 1,4-dioxane- $\mathrm{H}_{2} \mathrm{O}=2: 1$, and $\mathrm{NaOH}(88 \mathrm{mg}, 2.20 \mathrm{mmol})$ was added. The mixture was stirred at r.t. until consumption of $\mathbf{1 6 a}$ as monitored by TLC, and then the solvent was removed. The residue was re-dissolved in water, acidified with $2 \mathrm{~N}$ aqueous $\mathrm{HCl}$ to $\mathrm{pH} 3$ and then the product precipitated out. The precipitate was collected by filtration to afford $\mathbf{1 7 a}(227 \mathrm{mg}, 95 \%)$ and was carried forward without further purification. ${ }^{1} \mathrm{H}-\mathrm{NMR}$ $(300 \mathrm{MHz}, \mathrm{DMSO}) \delta: 12.25(1 \mathrm{H}, \mathrm{s}), 7.85(1 \mathrm{H}, \mathrm{s}), 7.36(2 \mathrm{H}, \mathrm{dd}$, $J=1.5,7.5 \mathrm{~Hz}), 7.12(1 \mathrm{H}, \mathrm{dt}, J=0.9 \mathrm{~Hz}, 7.5 \mathrm{~Hz}), 6.92(2 \mathrm{H}, \mathrm{m})$, $3.61(3 \mathrm{H}, \mathrm{s})$.

(4-Cyclopropyl-3,4-dihydroquinoxalin-1(2H)-yl)(1-methyl-5-phenoxy-1H-pyrazol-4-yl)methanone (18a) The title compound 18a was prepared as an off-white solid from 17a and 1-cyclopropyl-1,2,3,4-tetrahydroquinoxaline according to a procedure similar to the preparation of $13 \mathrm{c}$ from $12 \mathrm{c} . \mathrm{mp}$ $104^{\circ} \mathrm{C} .{ }^{1} \mathrm{H}-\mathrm{NMR}\left(300 \mathrm{MHz}, \mathrm{CDCl}_{3}\right) \delta: 7.54(1 \mathrm{H}, \mathrm{s}), 7.26(2 \mathrm{H}$, m), $7.15(1 \mathrm{H}, \mathrm{d}, J=8.1 \mathrm{~Hz}), 7.08(1 \mathrm{H}, \mathrm{d}, J=7.5 \mathrm{~Hz}), 7.02(1 \mathrm{H}, \mathrm{d}$, $J=8.4 \mathrm{~Hz}), 6.79(1 \mathrm{H}, \mathrm{d}, J=7.8 \mathrm{~Hz}), 6.75(2 \mathrm{H}, \mathrm{d}, J=8.1 \mathrm{~Hz}), 6.52$ $(1 \mathrm{H}, \mathrm{d}, J=7.5 \mathrm{~Hz}), 3.74(2 \mathrm{H}, \mathrm{t}, J=5.4 \mathrm{~Hz}), 3.60(3 \mathrm{H}, \mathrm{s}), 2.94$ $(2 \mathrm{H}, \mathrm{t}, J=5.4 \mathrm{~Hz}), 2.31(1 \mathrm{H}, \mathrm{m}), 0.77(2 \mathrm{H}, \mathrm{m}), 0.52(2 \mathrm{H}, \mathrm{m})$. ${ }^{13} \mathrm{C}-\mathrm{NMR}\left(126 \mathrm{MHz}, \mathrm{CDCl}_{3}\right) \delta: 160.92,156.47,146.70,140.20$, $139.36,129.78,125.67,125.26,123.50,123.21,116.29,115.03$, 112.86, 105.00, 48.34, 40.60, 34.61, 31.25, 7.97. HPLC-MS: $4.84 \mathrm{~min}, 375.3\left(\mathrm{M}+\mathrm{H}^{+}\right)$. HR-MS (ESI): $m / z\left(\mathrm{M}+\mathrm{H}^{+}\right)$Calcd for $\mathrm{C}_{22} \mathrm{H}_{23} \mathrm{O}_{2} \mathrm{~N}_{4}$ : 375.1816. Found: 375.1810 .

(4-Cyclopropyl-3,4-dihydroquinoxalin-1(2H)-yl)(5-(2,5dimethylphenoxy)-1-methyl-1 $H$-pyrazol-4-yl)methanone (18b) The title compound $\mathbf{1 8 b}$ was obtained as a white solid from 15 according to the general procedure that preparation of title compound 18a. mp $131^{\circ} \mathrm{C}$. ${ }^{1} \mathrm{H}-\mathrm{NMR}(300 \mathrm{MHz}$, $\left.\mathrm{CDCl}_{3}\right) \delta: 7.52(1 \mathrm{H}, \mathrm{s}), 7.10(1 \mathrm{H}, \mathrm{d}, J=8.1 \mathrm{~Hz}), 6.99(2 \mathrm{H}, \mathrm{m})$, $6.81(1 \mathrm{H}, \mathrm{d}, J=8.1 \mathrm{~Hz}), 6.76(1 \mathrm{H}, \mathrm{d}, J=7.5 \mathrm{~Hz}), 6.51(1 \mathrm{H}, \mathrm{d}$, $J=7.5 \mathrm{~Hz}), 6.37(1 \mathrm{H}, \mathrm{s}), 3.76(2 \mathrm{H}, \mathrm{t}, J=5.4 \mathrm{~Hz}), 3.57(3 \mathrm{H}, \mathrm{s})$, $3.00(2 \mathrm{H}, \mathrm{t}, J=5.4 \mathrm{~Hz}), 2.26(1 \mathrm{H}, \mathrm{m}), 2.20(3 \mathrm{H}, \mathrm{s}), 2.06(3 \mathrm{H}$, s), $0.74(2 \mathrm{H}, \mathrm{m}), 0.47(2 \mathrm{H}, \mathrm{m}) .{ }^{13} \mathrm{C}-\mathrm{NMR}\left(126 \mathrm{MHz}, \mathrm{CDCl}_{3}\right) \delta$ : $161.14,154.32,146.95,140.07,139.32,136.95,131.10,125.57$, $125.45,123.90,123.25,123.17,116.32,113.14,113.02,105.15$, 
48.47, 40.72, 34.53, 31.27, 21.13, 15.53, 7.88. HPLC-MS: $5.57 \mathrm{~min}, 403.3\left(\mathrm{M}+\mathrm{H}^{+}\right)$. HR-MS (ESI): $\mathrm{m} / \mathrm{z}\left(\mathrm{M}+\mathrm{H}^{+}\right)$Calcd for $\mathrm{C}_{24} \mathrm{H}_{27} \mathrm{O}_{2} \mathrm{~N}_{4}$ : 403.2129. Found: 403.2122 .

(4-Cyclopropyl-3,4-dihydroquinoxalin-1(2H)-yl)(5-(3methoxyphenoxy)-1-methyl-1 $H$-pyrazol-4-yl)methanone (18c) The title compound 18c was obtained from 15 according to the general procedure that preparation of title compound 18a. mp $58^{\circ} \mathrm{C}$. ${ }^{1} \mathrm{H}-\mathrm{NMR}\left(300 \mathrm{MHz}, \mathrm{CDCl}_{3}\right) \delta: 7.53$ $(1 \mathrm{H}, \mathrm{s}), 7.14(2 \mathrm{H}, \mathrm{m}), 7.03(1 \mathrm{H}, \mathrm{dt}, J=0.9,6.0 \mathrm{~Hz}), 6.80(1 \mathrm{H}, \mathrm{d}$, $J=6.0 \mathrm{~Hz}), 6.61(1 \mathrm{H}, \mathrm{m}), 6.51(1 \mathrm{H}, \mathrm{dt}, J=1.2,5.7,6.0 \mathrm{~Hz}), 6.32$ $(2 \mathrm{H}, \mathrm{m}), 3.76(2 \mathrm{H}, \mathrm{t}, J=4.2 \mathrm{~Hz}), 3.75(3 \mathrm{H}, \mathrm{s}), 3.60(3 \mathrm{H}, \mathrm{s}), 2.97$ $(2 \mathrm{H}, \mathrm{t}, J=4.2 \mathrm{~Hz}), 2.31(1 \mathrm{H}, \mathrm{m}), 0.78(2 \mathrm{H}, \mathrm{m}), 0.53(2 \mathrm{H}, \mathrm{m})$. ${ }^{13} \mathrm{C}-\mathrm{NMR}\left(126 \mathrm{MHz}, \mathrm{CDCl}_{3}\right) \delta: 160.94,160.85,157.45,146.55$, $140.16,139.44,130.20,125.69,125.25,123.24,116.30,112.91$, $109.08,106.88,105.09,101.70,55.41,48.35,40.64,34.62$, $31.21,7.96$. IR (KBr) cm $\mathrm{cm}^{-1}: 2925.24,1637.36,1607.05,1501.83$, 1489.73, 1430.37, 1130.12, 743.44. HPLC-MS: $4.90 \mathrm{~min}, 405.3$ $\left(\mathrm{M}+\mathrm{H}^{+}\right)$. HR-MS (ESI): $m / z\left(\mathrm{M}+\mathrm{H}^{+}\right)$Calcd for $\mathrm{C}_{23} \mathrm{H}_{25} \mathrm{O}_{3} \mathrm{~N}_{4}$ : 405.1921. Found: 405.1913.

Ethyl-5-hydroxy-1-(4-methoxybenzyl)-1 H-1,2,3-triazole4-carboxylate (19) Compound 19 was prepared as the literature described. ${ }^{26)}{ }^{1} \mathrm{H}-\mathrm{NMR}(300 \mathrm{MHz}, \mathrm{DMSO}) \delta: 7.20(2 \mathrm{H}$, $\mathrm{d}, J=6.3 \mathrm{~Hz}), 6.91(2 \mathrm{H}, \mathrm{d}, J=6.3 \mathrm{~Hz}), 5.27(2 \mathrm{H}, \mathrm{s}), 4.24(2 \mathrm{H}, \mathrm{q}$, $J=5.4 \mathrm{~Hz}), 3.72(1 \mathrm{H}, \mathrm{s}), 1.27(3 \mathrm{H}, \mathrm{t}, J=5.4 \mathrm{~Hz})$.

Ethyl-5-chloro-1-(4-methoxybenzyl)-1 H-1,2,3-triazole4-carboxylate (20) Compound 20 was synthesized from 19 with the method described in literature. ${ }^{27)}{ }^{1} \mathrm{H}-\mathrm{NMR}(300 \mathrm{MHz}$, $\left.\mathrm{CDCl}_{3}\right) \delta: 7.26(2 \mathrm{H}, \mathrm{d}, J=8.7 \mathrm{~Hz}), 6.87(2 \mathrm{H}, \mathrm{d}, J=8.7 \mathrm{~Hz})$, $5.50(2 \mathrm{H}, \mathrm{s}), 4.42(2 \mathrm{H}, \mathrm{q}, J=4.2 \mathrm{~Hz}), 3.79(1 \mathrm{H}, \mathrm{s}), 1.40(3 \mathrm{H}, \mathrm{t}$, $J=4.2 \mathrm{~Hz})$.

Ethyl-1-(4-methoxybenzyl)-5-(3-methoxyphenoxy)1H-1,2,3-triazole-4-carboxylate (21b) 3-Methoxyphenol $(334 \mu \mathrm{L}, 3.04 \mathrm{mmol})$ was dissolved in dry DMF, then cooled to $0^{\circ} \mathrm{C}$ and added $\mathrm{NaH}(60 \%, 90 \mathrm{mg}, 2.25 \mathrm{mmol})$. The reaction mixture was warmed to r.t. and stirred for $0.5 \mathrm{~h}$. The residue was treated with $20(600 \mathrm{mg}, 2.03 \mathrm{mmol})$ and held at $85^{\circ} \mathrm{C}$. After completion as monitored by TLC, the reaction was cooled to r.t. and slowly quenched with water. The resulting mixture was extracted twice with EtOAc, dried over $\mathrm{MgSO}_{4}$ and concentrated. The crude was purified by flash column chromatography to give $\mathbf{2 1 b}(576 \mathrm{mg})$ in $74 \%$ yield. ${ }^{1} \mathrm{H}-\mathrm{NMR}$ $\left(300 \mathrm{MHz}, \mathrm{CDCl}_{3}\right) \delta: 7.20(2 \mathrm{H}, \mathrm{d}, J=8.7 \mathrm{~Hz}), 7.14(1 \mathrm{H}, \mathrm{t}$, $J=8.7 \mathrm{~Hz}), 6.78(2 \mathrm{H}, \mathrm{d}, J=8.7 \mathrm{~Hz}), 6.64(1 \mathrm{H}, \mathrm{dd}, J=2.1,8.7 \mathrm{~Hz})$, $6.32(2 \mathrm{H}, \mathrm{m}), 5.33(2 \mathrm{H}, \mathrm{s}), 4.19(2 \mathrm{H}, \mathrm{q}, J=4.2 \mathrm{~Hz}), 3.75(3 \mathrm{H}, \mathrm{s})$, $3.71(3 \mathrm{H}, \mathrm{s}), 1.12(3 \mathrm{H}, \mathrm{t}, J=4.2 \mathrm{~Hz})$.

1-(4-Methoxybenzyl)-5-(3-methoxyphenoxy)-1 H-1,2,3triazole-4-carboxylic Acid (22b) Compound 22b (502 mg) was prepared from $\mathbf{2 1 b}(570 \mathrm{mg}, 1.49 \mathrm{mmol})$ according to the procedure described that preparation of $17 \mathbf{a}$ from $16 \mathbf{a}$ in excellent yield (95\%). ${ }^{1} \mathrm{H}-\mathrm{NMR}(300 \mathrm{MHz}, \mathrm{DMSO}) \delta$ : $12.99(1 \mathrm{H}$, br), $7.19(1 \mathrm{H}, \mathrm{t}, J=8.4 \mathrm{~Hz}), 7.14(2 \mathrm{H}, \mathrm{t}, J=8.7 \mathrm{~Hz}), 6.83(2 \mathrm{H}$, d, $J=8.7 \mathrm{~Hz}), 6.69(1 \mathrm{H}, \mathrm{ddd}, J=0.6,2.4,8.7 \mathrm{~Hz}), 6.42(1 \mathrm{H}, \mathrm{t}$, $J=2.4 \mathrm{~Hz}), 6.36(1 \mathrm{H}, \mathrm{ddd}, J=0.6,2.4,8.7 \mathrm{~Hz}) 5.35(2 \mathrm{H}, \mathrm{s}), 3.69$ $(3 \mathrm{H}, \mathrm{s}), 3.68(3 \mathrm{H}, \mathrm{s})$.

(4-Cyclopropyl-3,4-dihydroquinoxalin-1(2H)-yl)(1-(4methoxybenzyl)-5-(3-methoxyphenoxy)-1H-1,2,3-triazol-4yl)methanone (23b) The title compound 23b was obtained as a white solid from $\mathbf{2 2 b}$ following a similar procedure that preparation of $13 \mathrm{c}$ from 12c. mp $111^{\circ} \mathrm{C}$. ${ }^{1} \mathrm{H}-\mathrm{NMR}(300 \mathrm{MHz}$, $\left.\mathrm{CDCl}_{3}\right) \delta: 7.26-6.97(6 \mathrm{H}, \mathrm{m}), 6.76(2 \mathrm{H}, \mathrm{d}, J=7.8 \mathrm{~Hz}), 6.61(1 \mathrm{H}$, d, $J=7.8 \mathrm{~Hz}), 6.40(1 \mathrm{H}, \mathrm{m}), 6.19(2 \mathrm{H}, \mathrm{m}), 5.23(2 \mathrm{H}, \mathrm{s}), 3.88$
$(2 \mathrm{H}, \mathrm{m}), 3.76(3 \mathrm{H}, \mathrm{s}), 3.69(3 \mathrm{H}, \mathrm{s}), 2.91(2 \mathrm{H}, \mathrm{m}), 2.28(1 \mathrm{H}, \mathrm{m})$, $0.76(2 \mathrm{H}, \mathrm{m}), 0.51(2 \mathrm{H}, \mathrm{m}) \cdot{ }^{13} \mathrm{C}-\mathrm{NMR}\left(126 \mathrm{MHz}, \mathrm{CDCl}_{3}\right) \delta$ : $160.78,159.70,159.01,156.67,139.41,130.20,129.66,129.52$, $125.99,125.90,124.10,116.22,114.12,112.94,109.91,107.24$, $101.81,55.43,55.31,50.48,48.10,41.44,31.20$, 7.98. HPLCMS: $5.72 \mathrm{~min}, 512.3\left(\mathrm{M}+\mathrm{H}^{+}\right)$. HR-MS (ESI): $\mathrm{m} / \mathrm{z}\left(\mathrm{M}+\mathrm{H}^{+}\right)$ Calcd for $\mathrm{C}_{29} \mathrm{H}_{30} \mathrm{O}_{4} \mathrm{~N}_{5}$ : 512.2292. Found: 512.2285.

(4-Cyclopropyl-3,4-dihydroquinoxalin-1(2H)-yl)(5-(2,5dichlorophenoxy)-1-(4-methoxybenzyl)-1H-1,2,3-triazol-4yl)methanone (23a) The title compound 23a was obtained as a white solid with a similar method that preparation of the title compound 23b from 20. mp $119^{\circ} \mathrm{C}$. ${ }^{1} \mathrm{H}-\mathrm{NMR}(300 \mathrm{MHz}$, $\left.\mathrm{CDCl}_{3}\right) \delta: 7.26(2 \mathrm{H}, \mathrm{m}), 7.11(3 \mathrm{H}, \mathrm{m}), 7.01(1 \mathrm{H}, \mathrm{dt}, J=1.2$, $2.0 \mathrm{~Hz}), 6.95(1 \mathrm{H}, \mathrm{dd}, J=2.1,6.3 \mathrm{~Hz}), 6.72(2 \mathrm{H}, \mathrm{d}, J=6.3 \mathrm{~Hz})$, $6.54(1 \mathrm{H}, \mathrm{m}), 6.36(1 \mathrm{H}, \mathrm{m}), 5.31(2 \mathrm{H}, \mathrm{s}), 4.06(2 \mathrm{H}, \mathrm{m}), 3.75$ $(3 \mathrm{H}, \mathrm{s}), 3.28(2 \mathrm{H}, \mathrm{m}), 2.34(1 \mathrm{H}, \mathrm{m}), 0.77(2 \mathrm{H}, \mathrm{m}), 0.54(2 \mathrm{H}$, m). ${ }^{13} \mathrm{C}-\mathrm{NMR}\left(126 \mathrm{MHz}, \mathrm{CDCl}_{3}\right) \delta: 159.84,158.52,151.23$, $139.65,133.15,131.12,130.27,129.72,126.15,125.20,124.98$, $124.30,123.64,121.14,116.47,114.20,113.31,55.29,51.14$, 48.86, 31.34, 7.97. IR (KBr) $\mathrm{cm}^{-1}: 1642.80,1515.46,1497.38$, 1473.21, 1254.21. HPLC-MS: $6.37 \mathrm{~min}, 550.2\left(\mathrm{M}+\mathrm{H}^{+}\right)$. HR-MS (ESI): $m / z \quad\left(\mathrm{M}+\mathrm{H}^{+}\right)$Calcd for $\mathrm{C}_{28} \mathrm{H}_{26} \mathrm{O}_{3} \mathrm{~N}_{5} \mathrm{Cl}_{2}$ : 550.1407 . Found: 550.1403. HR-MS (ESI): $\mathrm{m} / \mathrm{z}\left(\mathrm{M}+\mathrm{H}^{+}\right)$Calcd for $\mathrm{C}_{28} \mathrm{H}_{26} \mathrm{O}_{3} \mathrm{~N}_{5} \mathrm{Cl}_{2}$ : 550.1407. Found: 550.1403 .

(5-(2,5-Dichlorophenoxy)-1-(4-methoxybenzyl)-1 H-1,2,3triazol-4-yl)(4-methyl-3,4-dihydro-quinoxalin-1(2H)-yl)methanone (24a) In addition to replaced1-cyclopropyl1,2,3,4-tetrahydroquinoxaline with 1-methyl-1,2,3,4-tetrahydroquinoxaline, the title compound $\mathbf{2 4 a}$ was obtained as a white solid with a similar method that preparation of the title compound 23b from 20. mp $116^{\circ} \mathrm{C}$. ${ }^{1} \mathrm{H}-\mathrm{NMR}(300 \mathrm{MHz}$, $\left.\mathrm{CDCl}_{3}\right) \delta: 7.26(2 \mathrm{H}, \mathrm{m}), 7.12(2 \mathrm{H}, \mathrm{m}), 7.02-6.94(2 \mathrm{H}, \mathrm{m}), 6.73$ $(2 \mathrm{H}, \mathrm{d}, J=8.4 \mathrm{~Hz}), 6.58(1 \mathrm{H}, \mathrm{d}, J=8.1 \mathrm{~Hz}), 6.45(1 \mathrm{H}, \mathrm{m}), 6.37$ $(1 \mathrm{H}, \mathrm{m}), 5.30(2 \mathrm{H}, \mathrm{s}), 4.05(2 \mathrm{H}, \mathrm{m}), 3.75(3 \mathrm{H}, \mathrm{s}), 3.19(2 \mathrm{H}, \mathrm{m})$, $2.83(3 \mathrm{H}, \mathrm{s}) .{ }^{13} \mathrm{C}-\mathrm{NMR}\left(126 \mathrm{MHz}, \mathrm{CDCl}_{3}\right) \delta: 159.83,158.52$, $151.17,139.43,133.16,131.07,130.09,129.73,126.62,125.24$, $124.96,123.90,121.17,116.23,115.72,114.20,111.52,55.29$, 51.14, 50.83, 37.93. IR (KBr) $\mathrm{cm}^{-1}: 1644.47,1514.06,1474.96$, 1248.25, 748.35. HPLC-MS: $5.88 \mathrm{~min}, 524.2\left(\mathrm{M}+\mathrm{H}^{+}\right)$. HR-MS (ESI): $m / z\left(\mathrm{M}+\mathrm{H}^{+}\right)$Calcd for $\mathrm{C}_{26} \mathrm{H}_{24} \mathrm{O}_{3} \mathrm{~N}_{5}$ : 524.1251. Found: 524.1251 .

(1-(4-Methoxybenzyl)-5-(3-methoxyphenoxy)-1H-1,2,3triazol-4-yl)(4-methyl-3,4-dihydro-quinoxalin-1(2H)-yl)methanone (24b) In addition to replaced 1-cyclopropyl1,2,3,4-tetrahydroquinoxaline with 1-methyl-1,2,3,4-tetrahydroquinoxaline, the title compound $\mathbf{2 4 b}$ was obtained as a white solid with a similar method that preparation of the title compound 23b from 20. mp $122^{\circ} \mathrm{C}$. ${ }^{1} \mathrm{H}-\mathrm{NMR}(300 \mathrm{MHz}$, $\left.\mathrm{CDCl}_{3}\right) \delta: 7.12-7.07(4 \mathrm{H}, \mathrm{m}), 7.00(1 \mathrm{H}, \mathrm{dt}, J=1.2,6.0 \mathrm{~Hz}), 6.76$ $(2 \mathrm{H}, \mathrm{d}, J=6.3 \mathrm{~Hz}), 6.62(1 \mathrm{H}, \mathrm{dd}, J=1.2,6.3 \mathrm{~Hz}), 6.57(1 \mathrm{H}$, d, $J=6.3 \mathrm{~Hz}), 6.33(1 \mathrm{H}, \mathrm{m}), 6.19(2 \mathrm{H}, \mathrm{m}), 5.23(2 \mathrm{H}, \mathrm{s}), 3.88$ $(2 \mathrm{H}, \mathrm{m}), 3.76(3 \mathrm{H}, \mathrm{s}), 3.70(3 \mathrm{H}, \mathrm{s}), 2.77(5 \mathrm{H}, \mathrm{m}) .{ }^{13} \mathrm{C}-\mathrm{NMR}$ $\left(126 \mathrm{MHz}, \mathrm{CDCl}_{3}\right) \delta: 160.79,159.69,158.95,156.61,139.22$, $130.10,129.64,129.13,126.42,126.08,123.60$, 115.33, 114.12, 110.86, 110.01, 107.17, 101.71, 55.44, 55.31, 50.43, 37.77. HPLCMS: $5.21 \mathrm{~min}, 486.3\left(\mathrm{M}+\mathrm{H}^{+}\right)$. HR-MS (ESI): $\mathrm{m} / \mathrm{z}\left(\mathrm{M}+\mathrm{H}^{+}\right)$ Calcd for $\mathrm{C}_{27} \mathrm{H}_{28} \mathrm{O}_{4} \mathrm{~N}_{5}$ : 486.2136. Found: 486.2123.

(5-(3-Methoxyphenoxy)-1H-1,2,3-triazol-4-yl)(4-methyl-3,4-dihydroquinoxalin-1(2H)-yl)methanone (25b) 24b (70 mg, $144 \mu \mathrm{mol}$ ) was dissolved in trifluoroacetic acid (TFA) $(5 \mathrm{~mL})$, then heated to $65^{\circ} \mathrm{C}$ and stirred for $2 \mathrm{~h}$. Upon comple- 
tion of reaction, the reaction mixture was cooled to r.t. and concentrated. The residue was then re-dissolved in DCM and washed with water. Then the solvent was removed under reduced pressure, and the crude reaction mixture was purified by preparative TLC to yield the title compound $25 \mathbf{b}$ (35 mg, $66 \%)$ as a light yellow solid. mp $157^{\circ} \mathrm{C} .{ }^{1} \mathrm{H}-\mathrm{NMR}(300 \mathrm{MHz}$, $\left.\mathrm{CDCl}_{3}\right) \delta: 7.18(1 \mathrm{H}, \mathrm{d}, J=8.4 \mathrm{~Hz}), 7.02(1 \mathrm{H}, \mathrm{d}, J=7.8 \mathrm{~Hz}), 6.61$ $(3 \mathrm{H}, \mathrm{m}), 6.36(3 \mathrm{H}, \mathrm{m}), 3.99(2 \mathrm{H}, \mathrm{m}), 3.73(3 \mathrm{H}, \mathrm{s}), 3.21(2 \mathrm{H}$, m), $2.87(3 \mathrm{H}, \mathrm{s})$. HPLC-MS: $3.98 \mathrm{~min}, 366.2\left(\mathrm{M}+\mathrm{H}^{+}\right)$. HR-MS (ESI): $m / z\left(\mathrm{M}+\mathrm{H}^{+}\right)$Calcd for $\mathrm{C}_{19} \mathrm{H}_{20} \mathrm{O}_{3} \mathrm{~N}_{5}$ : 366.1561. Found: 366.1556 .

(5-(2,5-Dichlorophenoxy)-1H-1,2,3-triazol-4-yl)(4-methyl-3,4-dihydroquinoxalin-1(2H)-yl)methanone (25a) The title compound 25a was prepared as a light yellow solid from 24a according to the similar procedure that preparation of the title compound $\mathbf{2 5 b}$ from $\mathbf{2 4 b}$. mp $149^{\circ} \mathrm{C} .{ }^{1} \mathrm{H}-\mathrm{NMR}(300 \mathrm{MHz}$, $\left.\mathrm{CDCl}_{3}\right) \delta: 7.23(1 \mathrm{H}, \mathrm{m}), 6.97(1 \mathrm{H}, \mathrm{m}), 6.88(1 \mathrm{H}, \mathrm{m}), 6.55-6.39$ $(4 \mathrm{H}, \mathrm{m}), 4.07(2 \mathrm{H}, \mathrm{d}, J=5.4 \mathrm{~Hz}), 3.48(2 \mathrm{H}, \mathrm{d}, J=5.4 \mathrm{~Hz})$, $2.87(3 \mathrm{H}, \mathrm{s}) .{ }^{13} \mathrm{C}-\mathrm{NMR}\left(126 \mathrm{MHz}, \mathrm{CDCl}_{3}\right) \delta: 150.77,139.67$, $132.79,130.65,127.13,124.97,123.73,123.02,122.27,118.83$ 115.33, 111.24, 50.73, 40.13, 37.90. IR (KBr) cm $\mathrm{cm}^{-1}$ : 1629.60, 1512.67, 1474.02, 1401.87, 1329.41, 1229.21, 733.17. HPLC-MS: $4.99 \mathrm{~min}, 404.1\left(\mathrm{M}+\mathrm{H}^{+}\right)$. HR-MS (ESI): $\mathrm{m} / z\left(\mathrm{M}+\mathrm{H}^{+}\right)$Calcd for $\mathrm{C}_{18} \mathrm{H}_{16} \mathrm{O}_{2} \mathrm{~N}_{5} \mathrm{Cl}_{2}$ : 404.0676. Found: 404.0664 .

Ethyl-4-hydroxy-2-methylthiazole-5-carboxylate Compound 26 was synthesized with the method described in the patent. ${ }^{28)}{ }^{1} \mathrm{H}-\mathrm{NMR}\left(300 \mathrm{MHz}, \mathrm{CDCl}_{3}\right) \delta: 9.88(1 \mathrm{H}, \mathrm{br}), 4.34$ $(2 \mathrm{H}, \mathrm{q}, J=7.2 \mathrm{~Hz}), 2.65(1 \mathrm{H}, \mathrm{s}), 1.35(3 \mathrm{H}, \mathrm{t}, J=7.2 \mathrm{~Hz})$.

Ethyl-4-(5-chloro-2-nitrophenoxy)-2-methylthiazole5-carboxylate (27a) To a solution of $\mathbf{2 6}$ in ethanol was added dropwise with fresh sodium ethoxide and then allowed to stir at $45^{\circ} \mathrm{C}$ for $0.5 \mathrm{~h}$. The reaction mixture was cooled to r.t. and filtered to give sodium salt of $26(2 \mathrm{~g}, 9.57 \mathrm{mmol})$. The residue was treated with 4-chloro-2-fluoro-1-nitrobenzene $(1.7 \mathrm{~g}, 9.71 \mathrm{mmol})$ in NMP and heated by microwave at $125^{\circ} \mathrm{C}$ for $2 \mathrm{~h}$. Then the reaction mixture was cooled to r.t., poured into water, extracted with EtOAc three times and combined the organic phases. The organic layer was washed with brine twice, dried over $\mathrm{MgSO}_{4}$, filtered and concentrated. The crude was purified by flash column chromatography to give compound 27a $(2.21 \mathrm{~g})$ in yield of $65 \%$. ${ }^{1} \mathrm{H}-\mathrm{NMR}(300 \mathrm{MHz}$, $\left.\mathrm{CDCl}_{3}\right) \delta: 8.02(1 \mathrm{H}, \mathrm{d}, J=8.7 \mathrm{~Hz}), 7.29(1 \mathrm{H}, \mathrm{dd}, J=2.1,8.7 \mathrm{~Hz})$, $7.27(2 \mathrm{H}, \mathrm{d}, J=2.1 \mathrm{~Hz}), 4.31(2 \mathrm{H}, \mathrm{q}, J=7.2 \mathrm{~Hz}), 2.57(3 \mathrm{H}, \mathrm{s})$ $1.32(3 \mathrm{H}, \mathrm{t}, J=7.2 \mathrm{~Hz})$.

Ethyl-4-(2-amino-5-chlorophenoxy)-2-methylthiazole5-carboxylate (28a) To a solution of $27 \mathbf{a}(1.37 \mathrm{~g}, 4.0 \mathrm{mmol})$ in $\mathrm{THF}-\mathrm{H}_{2} \mathrm{O}(2: 1)$ was added iron powder $(2.24 \mathrm{~g}, 40 \mathrm{mmol})$ and $\mathrm{NH}_{4} \mathrm{Cl}(2.14 \mathrm{~g}, 40 \mathrm{mmol})$, and then stirred at $65^{\circ} \mathrm{C}$ overnight. After completion of the reaction as monitored by TLC, the mixture was cooled to r.t., filtered by siliceousearth and the filter cake was washed with DCM. The filtrate was extracted with DCM and the organic layer was combined. The residue was evaporated under reduced pressure to give crude product 28a and was used directly in the next step without further purification. HPLC-MS: $313.13\left(\mathrm{M}+\mathrm{H}^{+}\right)$.

Ethyl-4-(2,5-dichlorophenoxy)-2-methylthiazole-5carboxylate (29a) To a solution of 28a (312 $\mathrm{mg}, 1.0 \mathrm{mmol})$ in $\mathrm{ACN}$ was added $\mathrm{CuCl}_{2}(202 \mathrm{mg}, 1.5 \mathrm{mmol})$, and slowly added ${ }^{t} \mathrm{BuONO}(238 \mu \mathrm{L}, 2.0 \mathrm{mmol})$. The reaction mixture was allowed to stir at r.t. for $24 \mathrm{~h}$, then heated to $60^{\circ} \mathrm{C}$ and stirring was continued for $2 \mathrm{~h}$. Upon completing, the reaction was quenched with $2 \mathrm{~N}$ aqueous $\mathrm{HCl}$ and diluted with water. The mixture was extracted with DCM $(3 \times)$ and the organic phases were combined. The combined organic layer was washed twice with brine, dried over $\mathrm{MgSO}_{4}$ and concentrated. The residue was purified by flash column chromatography to give the product 29a $(249 \mathrm{mg}, 75 \%)$. ${ }^{1} \mathrm{H}-\mathrm{NMR}\left(300 \mathrm{MHz}, \mathrm{CDCl}_{3}\right) \delta$ : $7.36(1 \mathrm{H}, \mathrm{d}, J=6.9 \mathrm{~Hz}), 7.11(1 \mathrm{H}, \mathrm{dd}, J=1.8,6.9 \mathrm{~Hz}), 7.10(1 \mathrm{H}$, d, $J=1.8 \mathrm{~Hz}), 4.31(2 \mathrm{H}, \mathrm{q}, J=5.4 \mathrm{~Hz}), 2.61(3 \mathrm{H}, \mathrm{s}), 1.32(3 \mathrm{H}, \mathrm{t}$, $J=5.4 \mathrm{~Hz})$.

Ethyl-4-(2-bromo-5-chlorophenoxy)-2-methylthiazole5-carboxylate (29c) In addition to use $\mathrm{CuBr}_{2}$ instead of $\mathrm{CuCl}_{2}, 29 \mathrm{c}$ was synthesized from 28a as following a similar procedure that preparation 29a from 28a. ${ }^{1} \mathrm{H}-\mathrm{NMR}(300 \mathrm{MHz}$, $\left.\mathrm{CDCl}_{3}\right) \delta: 7.52(1 \mathrm{H}, \mathrm{d}, J=6.0 \mathrm{~Hz}), 7.04(2 \mathrm{H}, \mathrm{m}), 4.31(2 \mathrm{H}, \mathrm{q}$, $J=5.4 \mathrm{~Hz}), 2.62(3 \mathrm{H}, \mathrm{s}), 1.31(3 \mathrm{H}, \mathrm{t}, J=5.4 \mathrm{~Hz})$.

Ethyl-4-(3-chlorophenoxy)-2-methylthiazole-5-carboxylate (29e) A solution of 28a $(312 \mathrm{mg}, 1.0 \mathrm{mmol})$ in $\mathrm{ACN}$, was treated with ${ }^{t} \mathrm{BuONO}$ and held at reflux for $8 \mathrm{~h}$. After the reaction was completed, the reaction mixture was cooled to r.t. and quenched with $2 \mathrm{~N}$ aqueous $\mathrm{HCl}$, then diluted with water. The crude mixture was extracted with EtOAc, and the combined organic layer was washed twice with brine, dried over $\mathrm{MgSO}_{4}$, filtered and concentrated under reduced pressure. The residue was purified by flash column chromatography to yield 29e (194 mg) in $65 \% .{ }^{1} \mathrm{H}-\mathrm{NMR}\left(300 \mathrm{MHz}, \mathrm{CDCl}_{3}\right) \delta: 7.27$ $(1 \mathrm{H}, \mathrm{t}, J=6.0 \mathrm{~Hz}), 7.12(1 \mathrm{H}, \mathrm{dd}, J=1.5,6.0 \mathrm{~Hz}), 7.09(1 \mathrm{H}, \mathrm{d}$, $J=1.5 \mathrm{~Hz}), 7.00(1 \mathrm{H}, \mathrm{dd}, J=1.5,6.0 \mathrm{~Hz}), 4.29(2 \mathrm{H}, \mathrm{q}, J=5.4 \mathrm{~Hz})$, $2.63(3 \mathrm{H}, \mathrm{s}), 1.30(3 \mathrm{H}, \mathrm{t}, J=5.1 \mathrm{~Hz})$.

4-(2,5-Dichlorophenoxy)-2-methylthiazole-5-carboxylic Acid The intermediate was prepared with the same method described that preparation of 17a from 16a. ${ }^{1} \mathrm{H}-\mathrm{NMR}$ (300 MHz, DMSO) $\delta$ : $13.21(1 \mathrm{H}$, br), $7.60(1 \mathrm{H}, \mathrm{d}, J=6.6 \mathrm{~Hz})$, $7.38(1 \mathrm{H}, \mathrm{d}, J=1.5 \mathrm{~Hz}), 7.31(1 \mathrm{H}, \mathrm{d}, J=1.5,6.6 \mathrm{~Hz}), 2.55(3 \mathrm{H}, \mathrm{s})$

4-(2-Bromo-5-chlorophenoxy)-2-methylthiazole-5-carboxylic Acid The intermediate was prepared with the same method described that preparation of $17 \mathbf{a}$ from $16 \mathbf{a} .{ }^{1} \mathrm{H}-\mathrm{NMR}$ (300 MHz, DMSO) $\delta$ : $13.19(1 \mathrm{H}$, br), $7.60(1 \mathrm{H}, \mathrm{d}, J=6.6 \mathrm{~Hz})$, $7.38(1 \mathrm{H}, \mathrm{d}, J=1.5 \mathrm{~Hz}), 7.31(1 \mathrm{H}, \mathrm{d}, J=1.5,6.6 \mathrm{~Hz}), 2.55(3 \mathrm{H}, \mathrm{s})$.

4-(3-Chlorophenoxy)-2-methylthiazole-5-carboxylic Acid The intermediate was prepared with the same method described that preparation of 17a from 16a. ${ }^{1} \mathrm{H}-\mathrm{NMR}(300 \mathrm{MHz}$, DMSO) $\delta$ : $13.18(1 \mathrm{H}, \mathrm{br}), 7.39(1 \mathrm{H}, \mathrm{t}, J=6.0 \mathrm{~Hz}), 7.22(1 \mathrm{H}, \mathrm{dd}$, $J=1.5,6.0 \mathrm{~Hz}), 7.17(1 \mathrm{H}, \mathrm{d}, J=1.5 \mathrm{~Hz}), 7.03(1 \mathrm{H}, \mathrm{dd}, J=1.5$, $6.0 \mathrm{~Hz}), 2.58(3 \mathrm{H}, \mathrm{s})$.

(4-Cyclopropyl-3,4-dihydroquinoxalin-1(2H)-yl)(4(2,5-dichlorophenoxy)-2-methylthiazol-5-yl)methanone (30c) The title compound 30c was prepared as a light yellow solid according to the general procedure that preparation of 13c from 12c. mp $160^{\circ} \mathrm{C} .{ }^{1} \mathrm{H}-\mathrm{NMR}\left(400 \mathrm{MHz}, \mathrm{CDCl}_{3}\right)$ $\delta$ : $7.21(1 \mathrm{H}, \mathrm{d}, J=8.6 \mathrm{~Hz}), 6.95-6.89(2 \mathrm{H}, \mathrm{m}), 6.85(1 \mathrm{H}, \mathrm{dd}$, $J=8.3,1.5 \mathrm{~Hz}), 6.79(1 \mathrm{H}, \mathrm{d}, J=7.9 \mathrm{~Hz}), 6.52(1 \mathrm{H}, \mathrm{ddd}, J=8.4$, $7.2,1.5 \mathrm{~Hz}), 6.13(1 \mathrm{H}, \mathrm{s}), 3.94(2 \mathrm{H}, \mathrm{t}, J=5.5 \mathrm{~Hz}), 3.49(2 \mathrm{H}, \mathrm{t}$, $J=5.5 \mathrm{~Hz}), 2.61(3 \mathrm{H}, \mathrm{s}), 2.30(1 \mathrm{H}, \mathrm{tt}, J=6.8,3.7 \mathrm{~Hz}), 0.74-0.68$ $(2 \mathrm{H}, \mathrm{m}), 0.45-0.39$ (2H, m). ${ }^{13} \mathrm{C}-\mathrm{NMR}\left(101 \mathrm{MHz}, \mathrm{CDCl}_{3}\right) \delta$ : $166.75,159.52,154.26,151.09,139.83,132.58,130.40,126.51$, $125.52,124.65,122.95,122.47,119.93,116.00,113.22,112.84$, $48.98,41.30,31.22,20.24,8.04$. IR $(\mathrm{KBr}) \mathrm{cm}^{-1}: 1646.23$, $1536.75,1506.15,1472.16,1405.36,1331.26,748.47$. HPLCMS: $6.49 \mathrm{~min}, 460.1\left(\mathrm{M}+\mathrm{H}^{+}\right)$. HR-MS (ESI): $\mathrm{m} / \mathrm{z}\left(\mathrm{M}+\mathrm{H}^{+}\right)$ Calcd for $\mathrm{C}_{22} \mathrm{H}_{19} \mathrm{Cl}_{2} \mathrm{~N}_{3} \mathrm{O}_{2} \mathrm{~S}$ : 460.0648. Found: 460.0661 .

(4-(2,5-Dichlorophenoxy)-2 -methylthiazol-5-yl)(4- 
methyl-3,4-dihydroquinoxalin-1(2H)-yl)methanone (30d) In addition to replaced 1-cyclopropyl-1,2,3,4-tetrahydroquinoxaline with 1-methyl-1,2,3,4-tetrahydro-quinoxaline, 30d was prepared as a light yellow solid according to the general procedure that preparation of $13 \mathrm{c}$ from $12 \mathrm{c} . \mathrm{mp} 126^{\circ} \mathrm{C}$. ${ }^{1} \mathrm{H}-\mathrm{NMR} \quad\left(300 \mathrm{MHz}, \mathrm{CDCl}_{3}\right) \quad \delta: 7.19 \quad(1 \mathrm{H}, \mathrm{d}, J=8.7 \mathrm{~Hz})$, $6.90(1 \mathrm{H}, \mathrm{dd}, J=2.4,8.4 \mathrm{~Hz}), 6.84(1 \mathrm{H}, \mathrm{dt}, J=1.2,7.8 \mathrm{~Hz})$, $6.74(1 \mathrm{H}, \mathrm{d}, J=7.2 \mathrm{~Hz}), 6.44(1 \mathrm{H}, \mathrm{dt}, J=1.2,7.2,7.8 \mathrm{~Hz})$, $6.24(1 \mathrm{H}, \mathrm{d}, J=7.8 \mathrm{~Hz}), 6.17(1 \mathrm{H}, \mathrm{s}), 3.99(2 \mathrm{H}, \mathrm{t}, J=5.4 \mathrm{~Hz})$, $3.49(2 \mathrm{H}, \mathrm{t}, J=5.4 \mathrm{~Hz}), 2.78(3 \mathrm{H}, \mathrm{s}), 2.63(3 \mathrm{H}, \mathrm{s}) .{ }^{13} \mathrm{C}-\mathrm{NMR}$ $\left(126 \mathrm{MHz}, \mathrm{CDCl}_{3}\right) \delta: 166.64,159.32,153.62,150.84,139.48$, $132.43,130.15,126.81,124.77,124.07,122.92,121.72,119.05$, $115.08,113.50,111.03,50.78,41.03,37.73,20.13$. IR $(\mathrm{KBr})$ $\mathrm{cm}^{-1}: 1640.10,1625.80,1512.29,1473.01,1407.68,1333.55$, 742.15. HPLC-MS: $6.01 \mathrm{~min}, 434.1\left(\mathrm{M}+\mathrm{H}^{+}\right)$. HR-MS (ESI): $m / z\left(\mathrm{M}+\mathrm{H}^{+}\right)$Calcd for $\mathrm{C}_{20} \mathrm{H}_{18} \mathrm{O}_{2} \mathrm{~N}_{3} \mathrm{Cl}_{2} \mathrm{~S}$ : 434.0491. Found: 434.0487 .

(4-(2-Chloro-5-methylphenoxy)-2-methylthiazol-5-yl)(4cyclopropyl-3,4-dihydroquinoxalin-1(2H)-yl)methanone (30a) The title compound 30a was obtained as a light yellow solid according to the general procedure that preparation of 13c from 12c. mp $136^{\circ} \mathrm{C} .{ }^{1} \mathrm{H}-\mathrm{NMR}\left(300 \mathrm{MHz}, \mathrm{CDCl}_{3}\right) \delta$ : 7.31 $(1 \mathrm{H}, \mathrm{dd}, J=1.2,7.2 \mathrm{~Hz}), 7.03-6.97(2 \mathrm{H}, \mathrm{m}), 6.92-6.88(3 \mathrm{H}, \mathrm{m})$, $6.51(1 \mathrm{H}, \mathrm{m}), 6.33(1 \mathrm{H}, \mathrm{m}), 3.96(2 \mathrm{H}, \mathrm{t}, J=5.4 \mathrm{~Hz}), 3.46(2 \mathrm{H}, \mathrm{t}$, $J=5.4 \mathrm{~Hz}), 2.59(3 \mathrm{H}, \mathrm{s}), 2.32(1 \mathrm{H}, \mathrm{m}), 0.71(2 \mathrm{H}, \mathrm{m}), 0.42(2 \mathrm{H}$, m). ${ }^{13} \mathrm{C}-\mathrm{NMR}\left(126 \mathrm{MHz}, \mathrm{CDCl}_{3}\right) \delta: 166.36,159.89,155.34$, $150.44,139.76,137.49,129.41,125.87,125.69,125.46,122.96$, $120.98,120.37,115.79,113.15,111.52,48.85,41.70,31.06$, 20.86, 20.11, 7.87. IR (KBr) $\mathrm{cm}^{-1}: 1628.74,1506.62,1415.80$, 1332.32, 1067.33, 757.53. HPLC-MS: $6.27 \mathrm{~min}, 440.2\left(\mathrm{M}+\mathrm{H}^{+}\right)$. HR-MS (ESI): $m / z \quad\left(\mathrm{M}+\mathrm{H}^{+}\right)$Calcd for $\mathrm{C}_{23} \mathrm{H}_{23} \mathrm{O}_{2} \mathrm{~N}_{3} \mathrm{ClS}$ : 440.1194. Found: 440.1189.

(4-(2-Chloro-5-methylphenoxy)-2-methylthiazol-5-yl)(4methyl-3,4-dihydroquinoxalin-1(2H)-yl)methanone (30b) In addition to replaced 1-cyclopropyl-1,2,3,4-tetrahydro-quinoxaline with 1-methyl-1,2,3,4-tetrahydro-quinoxaline, the title compound 30b was obtained as a light yellow solid according to the general procedure that preparation of $13 \mathrm{c}$ from $12 \mathrm{c} . \mathrm{mp}$ $137^{\circ} \mathrm{C} .{ }^{1} \mathrm{H}-\mathrm{NMR}\left(300 \mathrm{MHz}, \mathrm{CDCl}_{3}\right) \delta: 7.15(1 \mathrm{H}, \mathrm{d}, J=8.1 \mathrm{~Hz})$, 6.87-6.82 (2H, m), $6.75(1 \mathrm{H}, \mathrm{dd}, J=1.2,8.1 \mathrm{~Hz}), 6.45(1 \mathrm{H}, \mathrm{m})$, $6.32(1 \mathrm{H}, \mathrm{d}, J=7.8 \mathrm{~Hz}), 6.10(1 \mathrm{H}, \mathrm{s}), 4.00(2 \mathrm{H}, \mathrm{t}, J=5.4 \mathrm{~Hz})$, $3.46(2 \mathrm{H}, \mathrm{t}, J=5.4 \mathrm{~Hz}), 2.79(3 \mathrm{H}, \mathrm{s}), 2.60(3 \mathrm{H}, \mathrm{s}), 2.17(3 \mathrm{H}, \mathrm{s})$. ${ }^{13} \mathrm{C}-\mathrm{NMR}\left(126 \mathrm{MHz}, \mathrm{CDCl}_{3}\right) \delta: 166.38,159.83,154.93,150.41$, $139.61,137.46,129.36,126.30,125.10,123.09,120.50,119.75$, $118.32,115.11,112.21,111.30,50.84,41.58,37.87,20.93$, 20.12. HPLC-MS: $5.76 \mathrm{~min}, 414.2\left(\mathrm{M}+\mathrm{H}^{+}\right)$. HR-MS (ESI): $m / z$ $\left(\mathrm{M}+\mathrm{H}^{+}\right)$Calcd for $\mathrm{C}_{21} \mathrm{H}_{21} \mathrm{O}_{2} \mathrm{~N}_{3} \mathrm{ClS}$ : 414.1038. Found: 414.1031.

(4-(2-Bromo-5-chlorophenoxy)-2-methylthiazol-5-yl)(4cyclopropyl-3,4-dihydroquinoxalin-1(2H)-yl)methanone (30e) The title compound 30e was obtained as a light yellow solid according to the general procedure that preparation of 13c from 12c. mp $144^{\circ} \mathrm{C}$. ${ }^{1} \mathrm{H}-\mathrm{NMR}\left(300 \mathrm{MHz}, \mathrm{CDCl}_{3}\right)$ $\delta: 7.37(1 \mathrm{H}, \mathrm{d}, J=7.2 \mathrm{~Hz}), 6.94-6.76(4 \mathrm{H}, \mathrm{m}), 6.52(1 \mathrm{H}, \mathrm{dt}$, $J=1.5,7.5 \mathrm{~Hz}), 6.04(1 \mathrm{H}, \mathrm{s}), 3.93(2 \mathrm{H}, \mathrm{t}, J=5.4 \mathrm{~Hz}), 3.51(2 \mathrm{H}, \mathrm{t}$, $J=5.4 \mathrm{~Hz}), 2.61(3 \mathrm{H}, \mathrm{s}), 2.31(1 \mathrm{H}, \mathrm{m}), 0.71(2 \mathrm{H}, \mathrm{m}), 0.42(2 \mathrm{H}$, m). ${ }^{13} \mathrm{C}-\mathrm{NMR}\left(126 \mathrm{MHz}, \mathrm{CDCl}_{3}\right) \delta: 166.64,159.37,154.06$, $152.08,139.66,133.28,133.19,126.42,125.32,124.90,122.83$, $119.61,115.78,113.06,112.90,110.79,48.89,41.08,31.14$, 20.13, 7.94. IR (KBr) $\mathrm{cm}^{-1}: 1645.76,1534.69,1505.39,1466.46$, 1403.98, 1331.27, 747.58. HPLC-MS: $6.55 \mathrm{~min}, 504.1\left(\mathrm{M}+\mathrm{H}^{+}\right)$. HR-MS (ESI): $m / z \quad\left(\mathrm{M}+\mathrm{H}^{+}\right)$Calcd for $\mathrm{C}_{22} \mathrm{H}_{20} \mathrm{O}_{2} \mathrm{~N}_{3} \mathrm{BrClS}$ :
504.0143. Found: 504.0130.

(4-(2-Bromo-5-chlorophenoxy)-2-methylthiazol-5-yl)(4methyl-3,4-dihydroquinoxalin-1(2H)-yl)methanone (30f) In addition to replaced 1-cyclopropyl-1,2,3,4-tetrahydroquinoxaline with 1-methyl-1,2,3,4-tetrahydro-quinoxaline, the title compound 30e was obtained as a light yellow solid according to the general procedure that preparation of $13 \mathbf{c}$ from 12c. mp $134^{\circ} \mathrm{C} .{ }^{1} \mathrm{H}-\mathrm{NMR}\left(300 \mathrm{MHz}, \mathrm{CDCl}_{3}\right) \delta$ : $7.35(1 \mathrm{H}, \mathrm{d}$, $J=8.4 \mathrm{~Hz}), 6.86-6.82(2 \mathrm{H}, \mathrm{m}), 6.73(1 \mathrm{H}, \mathrm{d}, J=8.1 \mathrm{~Hz}), 6.44$ $(1 \mathrm{H}, \mathrm{d}, J=7.8 \mathrm{~Hz}), 6.21(1 \mathrm{H}, \mathrm{d}, J=8.4 \mathrm{~Hz}), 6.10(1 \mathrm{H}, \mathrm{s}), 3.99$ $(2 \mathrm{H}, \mathrm{t}, J=5.4 \mathrm{~Hz}), 3.51(2 \mathrm{H}, \mathrm{t}, J=5.4 \mathrm{~Hz}), 2.78(3 \mathrm{H}, \mathrm{s}), 2.63$ $(3 \mathrm{H}, \mathrm{s}) .{ }^{13} \mathrm{C}-\mathrm{NMR}\left(126 \mathrm{MHz}, \mathrm{CDCl}_{3}\right) \delta: 166.66,159.30,153.57$, $151.95,146.03,139.46,133.25,133.09,126.86,124.74,124.46$, $122.93,118.91,115.02,113.71,111.00,50.80,40.98,37.79$, 20.14. HPLC-MS: $6.09 \mathrm{~min}, 478.1\left(\mathrm{M}+\mathrm{H}^{+}\right)$. HR-MS (ESI): $m / z\left(\mathrm{M}+\mathrm{H}^{+}\right)$Calcd for $\mathrm{C}_{20} \mathrm{H}_{18} \mathrm{O}_{2} \mathrm{~N}_{3} \mathrm{BrClS}$ : 477.9986. Found: 477.9980 .

(4-(2-Bromo-5-methylphenoxy)-2-methylthiazol-5-yl)(4cyclopropyl-3,4-dihydroquinoxalin-1(2H)-yl)methanone (30g) The title compound $30 \mathrm{~g}$ was obtained as a light yellow solid according to the general procedure that preparation of 13c from 12c. mp $133^{\circ} \mathrm{C} .{ }^{1} \mathrm{H}-\mathrm{NMR}\left(300 \mathrm{MHz}, \mathrm{CDCl}_{3}\right) \delta: 7.32$ $(1 \mathrm{H}, \mathrm{d}, J=6.0 \mathrm{~Hz}), 6.88(3 \mathrm{H}, \mathrm{m}), 6.71(1 \mathrm{H}, \mathrm{dd}, J=0.9,6.0 \mathrm{~Hz})$, $6.53(1 \mathrm{H}, \mathrm{m}), 5.95(1 \mathrm{H}, \mathrm{d}, J=0.9 \mathrm{~Hz}), 3.95(2 \mathrm{H}, \mathrm{t}, J=4.2 \mathrm{~Hz})$, $3.50(2 \mathrm{H}, \mathrm{t}, J=4.2 \mathrm{~Hz}), 2.59(3 \mathrm{H}, \mathrm{s}), 2.31(1 \mathrm{H}, \mathrm{m}), 2.15(3 \mathrm{H}$, s), $0.69(2 \mathrm{H}, \mathrm{m}), 0.41(2 \mathrm{H}, \mathrm{m}) .{ }^{13} \mathrm{C}-\mathrm{NMR}\left(126 \mathrm{MHz}, \mathrm{CDCl}_{3}\right)$ $\delta$ : 166.37, 159.86, 155.25, 151.56, 139.74, 138.26, 132.38, $125.89,125.66,122.97,120.24,118.57,115.68,113.14,111.76$, 109.53, 48.89, 41.56, 31.08, 20.88, 20.13, 7.90. IR (KBr) cm$~^{-1}$ : 1628.27, 1526.51, 1505.97, 1480.77, 1413.50, 1331.67, 1308.91, 756.78. HPLC-MS: $6.33 \mathrm{~min}, 484.2\left(\mathrm{M}+\mathrm{H}^{+}\right)$. HR-MS (ESI): $m / z \quad\left(\mathrm{M}+\mathrm{H}^{+}\right)$Calcd for $\mathrm{C}_{23} \mathrm{H}_{23} \mathrm{O}_{2} \mathrm{~N}_{3} \mathrm{BrS}$ : 484.0689. Found: 484.0683 .

(4-(2-Bromo-5-methylphenoxy)-2-methylthiazol-5-yl)(4methyl-3,4-dihydroquinoxalin-1(2H)-yl)methanone $\quad(30 \mathrm{~h})$ In addition to replaced 1-cyclopropyl-1,2,3,4-tetrahydroquinoxaline with 1-methyl-1,2,3,4-tetrahydro-quinoxaline, the title compound $\mathbf{3 0 h}$ was obtained as a light yellow solid according to the general procedure that preparation of $\mathbf{1 3 c}$ from 12c. mp $129^{\circ} \mathrm{C}$. ${ }^{1} \mathrm{H}-\mathrm{NMR}\left(300 \mathrm{MHz}, \mathrm{CDCl}_{3}\right) \delta: 7.32$ $(1 \mathrm{H}, \mathrm{d}, J=6.0 \mathrm{~Hz}), 6.88(3 \mathrm{H}, \mathrm{m}), 6.71(1 \mathrm{H}, \mathrm{dd}, J=0.9,6.0 \mathrm{~Hz})$, $6.53(1 \mathrm{H}, \mathrm{m}), 6.10(1 \mathrm{H}, \mathrm{s}), 3.99(2 \mathrm{H}, \mathrm{t}, J=5.4 \mathrm{~Hz}), 3.49(2 \mathrm{H}, \mathrm{t}$, $J=5.4 \mathrm{~Hz}), 2.79(3 \mathrm{H}, \mathrm{s}), 2.60(3 \mathrm{H}, \mathrm{s}), 2.13(3 \mathrm{H}, \mathrm{s}) .{ }^{13} \mathrm{C}-\mathrm{NMR}$ $\left(126 \mathrm{MHz}, \mathrm{CDCl}_{3}\right) \delta: 166.52,159.81,154.82,151.51,139.61$, $138.21,132.33,128.75,126.32,125.53,124.93,122.99,119.62$, 117.76, 115.02, 111.28, 50.85, 41.16, 37.90, 20.96, 20.13. HPLCMS: $6.16 \mathrm{~min}, 458.1\left(\mathrm{M}+\mathrm{H}^{+}\right)$. HR-MS (ESI): $\mathrm{m} / \mathrm{z}\left(\mathrm{M}+\mathrm{H}^{+}\right)$ Calcd for $\mathrm{C}_{21} \mathrm{H}_{21} \mathrm{O}_{2} \mathrm{~N}_{3} \mathrm{BrS}$ : 458.0532. Found: 458.0531.

(4-Cyclopropyl-3,4-dihydroquinoxalin-1(2H)-yl)(2methyl-4-(m-tolyloxy)thiazol-5-yl)methanone (30i) The title compound 30i was obtained ass a light yellow solid according to the general procedure that preparation of $13 \mathbf{c}$ from 12c. mp $116^{\circ} \mathrm{C}$. ${ }^{1} \mathrm{H}-\mathrm{NMR}\left(300 \mathrm{MHz}, \mathrm{CDCl}_{3}\right) \quad \delta: 7.10$ $(1 \mathrm{H}, \mathrm{t}, J=7.8 \mathrm{~Hz}), 7.01-6.91(3 \mathrm{H}, \mathrm{m}), 6.81(1 \mathrm{H}, \mathrm{d}, J=7.8 \mathrm{~Hz})$, 6.55-6.50 (2H, m), $6.47(1 \mathrm{H}, \mathrm{s}), 3.92(2 \mathrm{H}, \mathrm{t}, J=5.4 \mathrm{~Hz}), 3.38$ $(2 \mathrm{H}, \mathrm{t}, J=5.4 \mathrm{~Hz}), 2.60(3 \mathrm{H}, \mathrm{s}), 2.30(1 \mathrm{H}, \mathrm{m}), 0.74(2 \mathrm{H}, \mathrm{m})$, $0.42(2 \mathrm{H}, \mathrm{m}) .{ }^{13} \mathrm{C}-\mathrm{NMR}\left(126 \mathrm{MHz}, \mathrm{CDCl}_{3}\right) \delta: 166.49,159.61$, $155.78,154.88,139.93,134.37,129.81,126.23,125.85,123.81$, $122.70,118.58,116.32,116.21,113.21,112.50,48.95,41.51$, $31.15,20.09$, 7.92. IR $(\mathrm{KBr}) \mathrm{cm}^{-1}: 1622.93,1591.20,1506.27$, 1406.76, 1332.96, 1214.85, 1086.47, 746.28. HPLC-MS: 
$6.18 \mathrm{~min}, 426.2\left(\mathrm{M}+\mathrm{H}^{+}\right)$. HR-MS (ESI): $m / z\left(\mathrm{M}+\mathrm{H}^{+}\right)$Calcd for $\mathrm{C}_{22} \mathrm{H}_{21} \mathrm{O}_{2} \mathrm{~N}_{3} \mathrm{ClS}: 426.1038$. Found: 426.1033.

(4-Cyclopropyl-3,4-dihydroquinoxalin-1(2H)-yl)(2methyl-4-(m-tolyloxy)thiazol-5-yl)methanone (30j) The title compound $\mathbf{3 0} \mathbf{j}$ was obtained as a light yellow solid according to the general procedure that preparation of $13 \mathrm{c}$ from $12 \mathrm{c}$ mp $110^{\circ} \mathrm{C} .{ }^{1} \mathrm{H}-\mathrm{NMR}\left(300 \mathrm{MHz}, \mathrm{CDCl}_{3}\right) \delta$ : $7.09-6.94(3 \mathrm{H}$, $\mathrm{m}), 6.88(1 \mathrm{H}, \mathrm{d}, J=7.8 \mathrm{~Hz}), 6.83(1 \mathrm{H}, \mathrm{d}, J=7.5 \mathrm{~Hz}), 6.57-6.51$ $(1 \mathrm{H}, \mathrm{m}), 6.42(1 \mathrm{H}, \mathrm{m}), 6.34(1 \mathrm{H}, \mathrm{s}), 3.92(2 \mathrm{H}, \mathrm{t}, J=5.7 \mathrm{~Hz})$ $3.36(2 \mathrm{H}, \mathrm{t}, J=5.7 \mathrm{~Hz}), 2.58(3 \mathrm{H}, \mathrm{s}), 2.30(1 \mathrm{H}, \mathrm{m}), 2.24(3 \mathrm{H}$, s), $0.71(2 \mathrm{H}, \mathrm{m}), 0.41(2 \mathrm{H}, \mathrm{m}) .{ }^{13} \mathrm{C}-\mathrm{NMR}\left(126 \mathrm{MHz}, \mathrm{CDCl}_{3}\right) \delta$ : $166.28,160.07,155.99,155.41,139.87,139.19,128.82,125.98$, $125.91,124.49,122.83,118.68,116.25,115.13,113.19,111.65$, $48.86,41.83,31.08,21.28,20.10,7.89$. IR (KBr) cm ${ }^{-1}: 1623.00$, 1506.34, 1405.22, 1334.80, 1306.90, 1248.01, 1146.39, 746.32. HPLC-MS: $5.98 \mathrm{~min}, 406.2\left(\mathrm{M}+\mathrm{H}^{+}\right)$. HR-MS (ESI): $\mathrm{m} / \mathrm{z}$ $\left(\mathrm{M}+\mathrm{H}^{+}\right)$Calcd for $\mathrm{C}_{23} \mathrm{H}_{24} \mathrm{O}_{2} \mathrm{~N}_{3} \mathrm{~S}: 406.1584$. Found: 406.1578 .

(4-Cyclopropyl-3,4-dihydroquinoxalin-1(2H)-yl)(4-(2,4dichlorophenoxy)-2-methylthiazol-5-yl)methanone (30k) The title compound 30k was synthesized as a light yellow solid in a manner similar to the title compound 30c. $\mathrm{mp}$ $87^{\circ} \mathrm{C} .{ }^{1} \mathrm{H}-\mathrm{NMR}(400 \mathrm{MHz}, \mathrm{CDCl} 3) \delta: 7.31(1 \mathrm{H}, \mathrm{d}, J=2.5 \mathrm{~Hz})$, $6.98(1 \mathrm{H}, \mathrm{dd}, J=8.8,2.6 \mathrm{~Hz}), 6.95-6.88(2 \mathrm{H}, \mathrm{m}), 6.85(1 \mathrm{H}$, d, $J=8.0 \mathrm{~Hz}), 6.50(1 \mathrm{H}, \mathrm{ddd}, J=8.2,6.5,2.2 \mathrm{~Hz}), 6.22(1 \mathrm{H}$, $\mathrm{d}, J=8.8 \mathrm{~Hz}), 3.95(2 \mathrm{H}, \mathrm{t}, J=5.5 \mathrm{~Hz}), 3.47(2 \mathrm{H}, \mathrm{t}, J=5.5 \mathrm{~Hz})$, $2.57(3 \mathrm{H}, \mathrm{s}), 2.33(1 \mathrm{H}, \mathrm{tt}, J=6.8,3.7 \mathrm{~Hz}), 0.77-0.70(2 \mathrm{H}, \mathrm{m})$, 0.46-0.39 (2H, m). ${ }^{13} \mathrm{C}-\mathrm{NMR}\left(126 \mathrm{MHz}, \mathrm{CDCl}_{3}\right) \delta: 166.48$, $159.60,154.91,149.57,139.83,129.58,129.30,127.36,126.12$, $125.72,125.23,122.77,121.00,115.99,113.18,111.48,48.86$, 41.56, 31.10, 20.05, 7.97. HPLC-MS: $6.62 \mathrm{~min}, 460.1\left(\mathrm{M}+\mathrm{H}^{+}\right)$. HR-MS (ESI): $m / z \quad\left(\mathrm{M}+\mathrm{H}^{+}\right)$Calcd for $\mathrm{C}_{22} \mathrm{H}_{20} \mathrm{O}_{2} \mathrm{~N}_{3} \mathrm{Cl}_{2} \mathrm{~S}$ : 460.0648. Found: 460.0641 .

(4-(4-Chlorophenoxy)-2-methylthiazol-5-yl)(4-cyclopropyl-3,4-dihydroquinoxalin-1(2H)-yl)methanone (30l) The title compound $\mathbf{3 0 1}$ was synthesized as a light yellow solid in a manner similar to the title compound $30 \mathrm{i}$. $\mathrm{mp} 88^{\circ} \mathrm{C}$. ${ }^{1} \mathrm{H}-\mathrm{NMR}(400 \mathrm{MHz}, \mathrm{CDCl} 3) \delta$ : 7.16-7.11 (2H, m), 7.03-6.94 $(2 \mathrm{H}, \mathrm{m}), 6.83(1 \mathrm{H}, \mathrm{d}, J=7.9 \mathrm{~Hz}), 6.52(3 \mathrm{H}, \mathrm{ddd}, J=12.6$, $7.8,1.8 \mathrm{~Hz}), 3.93(2 \mathrm{H}, \mathrm{t}, J=5.6 \mathrm{~Hz}), 3.38(2 \mathrm{H}, \mathrm{t}, J=5.6 \mathrm{~Hz})$, $2.58(3 \mathrm{H}, \mathrm{s}), 2.31(1 \mathrm{H}, \mathrm{tt}, J=6.7,3.7 \mathrm{~Hz}), 0.77-0.71(2 \mathrm{H}, \mathrm{m})$, 0.44-0.38 (2H, m). ${ }^{13} \mathrm{C}-\mathrm{NMR}\left(126 \mathrm{MHz}, \mathrm{CDCl}_{3}\right) \delta: 166.43$, $159.76,155.50,153.83,140.00,129.09,128.85,126.09,122.71$, 119.71, 116.35, 113.26, 111.62, 48.94, 41.62, 31.14, 20.07, 7.96. HPLC-MS: $6.18 \mathrm{~min}, 426.2\left(\mathrm{M}+\mathrm{H}^{+}\right)$. HR-MS (ESI): $\mathrm{m} / \mathrm{z}$ $\left(\mathrm{M}+\mathrm{H}^{+}\right)$Calcd for $\mathrm{C}_{22} \mathrm{H}_{21} \mathrm{O}_{2} \mathrm{~N}_{3} \mathrm{ClS}: 426.1038$. Found: 426.1035 .

(4-(2-Chlorophenoxy)-2-methylthiazol-5-yl)(4-cyclopropyl-3,4-dihydroquinoxalin-1(2H)-yl)methanone $\quad(30 \mathrm{~m})$ The title compound $\mathbf{3 0 m}$ was synthesized as a yellow solid in a manner similar to the title compound 30c. mp $93^{\circ} \mathrm{C}$. ${ }^{1} \mathrm{H}-\mathrm{NMR}\left(300 \mathrm{MHz}, \mathrm{CDCl}_{3}\right) \delta: 7.31(1 \mathrm{H}, \mathrm{dd}, J=1.2,7.2 \mathrm{~Hz})$, $7.03-6.97(2 \mathrm{H}, \mathrm{m}), 6.92-6.88(3 \mathrm{H}, \mathrm{m}), 6.51(1 \mathrm{H}, \mathrm{m}), 6.33(1 \mathrm{H}$, m), $3.96(2 \mathrm{H}, \mathrm{t}, J=5.4 \mathrm{~Hz}), 3.46(2 \mathrm{H}, \mathrm{t}, J=5.4 \mathrm{~Hz}), 2.59(3 \mathrm{H}, \mathrm{s})$, $2.32(1 \mathrm{H}, \mathrm{m}), 0.71(2 \mathrm{H}, \mathrm{m}), 0.42(2 \mathrm{H}, \mathrm{m}) .{ }^{13} \mathrm{C}-\mathrm{NMR}(126 \mathrm{MHz}$, $\left.\mathrm{CDCl}_{3}\right) \quad \delta: 166.37,159.85,155.32,150.87,139.77,129.98$ $127.28,126.01,125.68,124.73,124.34,122.86,120.07,116.00$, $113.15,111.39,48.83,41.79,31.08,20.07,7.90$. HPLC-MS: $5.94 \mathrm{~min}, 426.2\left(\mathrm{M}+\mathrm{H}^{+}\right)$. HR-MS (ESI): $m / z\left(\mathrm{M}+\mathrm{H}^{+}\right)$Calcd for $\mathrm{C}_{22} \mathrm{H}_{21} \mathrm{O}_{2} \mathrm{~N}_{3} \mathrm{ClS}:$ 426.1038. Found: 426.1029 .

(4-(4-Bromo-2,5-dichlorophenoxy)-2-methylthiazol-5yl)(4-cyclopropyl-3,4-dihydroquinoxalin-1(2H)-yl)methanone (30n) The title compound 30n was synthesized as a light yellow solid in a manner similar to the title compound 30e. mp $128^{\circ} \mathrm{C}$. ${ }^{1} \mathrm{H}-\mathrm{NMR}\left(300 \mathrm{MHz}, \mathrm{CDCl}_{3}\right) \delta$ : $7.31(1 \mathrm{H}, \mathrm{dd}$, $J=1.2,7.2 \mathrm{~Hz}), 7.03-6.97(2 \mathrm{H}, \mathrm{m}), 6.92-6.88(3 \mathrm{H}, \mathrm{m}), 6.51$ $(1 \mathrm{H}, \mathrm{m}), 6.33(1 \mathrm{H}, \mathrm{m}), 3.96(2 \mathrm{H}, \mathrm{t}, J=5.4 \mathrm{~Hz}), 3.46(2 \mathrm{H}, \mathrm{t}$, $J=5.4 \mathrm{~Hz}), 2.59(3 \mathrm{H}, \mathrm{s}), 2.32(1 \mathrm{H}, \mathrm{m}), 0.71(2 \mathrm{H}, \mathrm{m}), 0.42(2 \mathrm{H}$, m). ${ }^{13} \mathrm{C}-\mathrm{NMR}\left(126 \mathrm{MHz}, \mathrm{CDCl}_{3}\right) \delta: 166.74,159.21,153.82$, $150.10,139.74,133.34,132.81,126.43,125.40,123.27,122.79$, $120.98,116.54,115.86,113.13,112.73,48.85,41.15,31.12$, 20.10, 7.97. HPLC-MS: $7.14 \mathrm{~min}, 538.1\left(\mathrm{M}+\mathrm{H}^{+}\right)$. HR-MS (ESI): $m / z\left(\mathrm{M}+\mathrm{H}^{+}\right)$Calcd for $\mathrm{C}_{22} \mathrm{H}_{19} \mathrm{O}_{2} \mathrm{~N}_{3} \mathrm{BrCl}_{2} \mathrm{~S}$ : 537.9753 . Found: 537.9753

(4-(5-Chloro-2-methylphenoxy)-2-methylthiazol-5-yl)(4cyclopropyl-3,4-dihydroquinoxalin-1(2H)-yl)methanone (31a) To a solution of $\mathbf{3 0 e}(102 \mathrm{mg}, 0.2 \mathrm{mmol})$ in dry 1,4-dioxane, was added $\mathrm{Zn}\left(\mathrm{CH}_{3}\right)_{2} \quad(333 \mu \mathrm{L}, 0.4 \mathrm{mmol})$ and $\mathrm{PdCl}_{2}$ (dppf) $\cdot \mathrm{CH}_{2} \mathrm{Cl}_{2}$ (16.3 mg, $\left.0.02 \mathrm{mmol}\right)$. The reaction mixture was stirred at reflux under an atmosphere of nitrogen for $2 \mathrm{~h}$. After completion, the reaction was quenched with $\mathrm{CH}_{3} \mathrm{OH}$ and stirring was continued for $10 \mathrm{~min}$. The precipitate was removed by filtration and the filtrate was concentrated under reduced pressure. The residue was purified to give the title compound 31a (71 mg) as a light yellow solid in yield of $81 \%$. mp $98^{\circ} \mathrm{C}$. ${ }^{1} \mathrm{H}-\mathrm{NMR}\left(300 \mathrm{MHz}, \mathrm{CDCl}_{3}\right) \delta$ : $7.01-6.89(4 \mathrm{H}$, m), $6.83(1 \mathrm{H}, \mathrm{d}, J=5.7 \mathrm{~Hz}), 6.56(1 \mathrm{H}, \mathrm{dt}, J=1.2,5.7 \mathrm{~Hz}), 6.05$ $(1 \mathrm{H}, \mathrm{s}), 3.93(2 \mathrm{H}, \mathrm{t}, J=4.2 \mathrm{~Hz}), 3.42(2 \mathrm{H}, \mathrm{t}, J=4.2 \mathrm{~Hz}), 2.59$ $(3 \mathrm{H}, \mathrm{s}), 2.27(1 \mathrm{H}, \mathrm{m}), 2.04(3 \mathrm{H}, \mathrm{s}), 0.70(2 \mathrm{H}, \mathrm{m}), 0.35(2 \mathrm{H}, \mathrm{m})$. ${ }^{13} \mathrm{C}-\mathrm{NMR}\left(126 \mathrm{MHz}, \mathrm{CDCl}_{3}\right) \delta: 166.49,159.81,155.52,153.78$, $139.81,131.31,131.17,126.43,126.37,125.83,123.80,122.81$, 118.27, 116.26, 113.26, 111.54, 49.06, 41.37, 31.08, 20.11, 15.76, 7.83. HPLC-MS: $6.43 \mathrm{~min}, 440.2\left(\mathrm{M}+\mathrm{H}^{+}\right)$. HR-MS (ESI): $\mathrm{m} / \mathrm{z}$ $\left(\mathrm{M}+\mathrm{H}^{+}\right)$Calcd for $\mathrm{C}_{23} \mathrm{H}_{23} \mathrm{O}_{2} \mathrm{~N}_{3} \mathrm{ClS}: 440.1194$. Found: 440.1190 .

(4-Cyclopropyl-3,4-dihydroquinoxalin-1(2H)-yl)(4-(2,5dimethylphenoxy)-2-methylthiazol-5-yl)methanone (31b) The title compound $\mathbf{3 1 b}$ was prepared as a light yellow solid from $30 \mathrm{~g}$ according to the similar procedure that preparation of 31a from 30e. mp $90^{\circ} \mathrm{C} .{ }^{1} \mathrm{H}-\mathrm{NMR}\left(300 \mathrm{MHz}, \mathrm{CDCl}_{3}\right)$ $\delta: 6.98-6.96(3 \mathrm{H}, \mathrm{m}), 6.92(1 \mathrm{H}, \mathrm{d}, J=6.0 \mathrm{~Hz}), 6.75(1 \mathrm{H}, \mathrm{d}$, $J=6.0 \mathrm{~Hz}), 6.56(1 \mathrm{H}, \mathrm{m}), 5.99(1 \mathrm{H}, \mathrm{s}), 3.94(2 \mathrm{H}, \mathrm{t}, J=4.2 \mathrm{~Hz})$, $3.39(2 \mathrm{H}, \mathrm{t}, J=4.2 \mathrm{~Hz}), 2.57(3 \mathrm{H}, \mathrm{s}), 2.29(1 \mathrm{H}, \mathrm{m}), 2.17(3 \mathrm{H}, \mathrm{s})$, $2.01(3 \mathrm{H}, \mathrm{s}), 0.69(2 \mathrm{H}, \mathrm{m}), 0.37(2 \mathrm{H}, \mathrm{m}) .{ }^{13} \mathrm{C}-\mathrm{NMR}(126 \mathrm{MHz}$, $\left.\mathrm{CDCl}_{3}\right) \quad \delta: 166.28,160.28,156.60,153.52,139.80,136.27$, $130.36,126.03,125.87,124.88,124.65,122.86,118.70,116.18$, 113.27, 110.54, 48.94, 41.77, 31.08, 20.87, 20.13, 15.76, 7.83. HPLC-MS: $6.29 \mathrm{~min}, 420.3\left(\mathrm{M}+\mathrm{H}^{+}\right)$. HR-MS (ESI): $\mathrm{m} / \mathrm{z}$ $\left(\mathrm{M}+\mathrm{H}^{+}\right)$Calcd for $\mathrm{C}_{24} \mathrm{H}_{26} \mathrm{O}_{2} \mathrm{~N}_{3} \mathrm{~S}: 420.1740$. Found: 420.1732 .

(4-Cyclopropyl-3,4-dihydroquinoxalin-1(2H)-yl)(4-(2,5dichloro-4-methylphenoxy)-2-methylthiazol-5-yl)methanone (31c) The title compound 31c was prepared from 30n according to the similar procedure that preparation of 31a from 30e. mp $167^{\circ} \mathrm{C}$. ${ }^{1} \mathrm{H}-\mathrm{NMR}\left(400 \mathrm{MHz}, \mathrm{CDCl}_{3}\right) \delta: 7.16$ $(1 \mathrm{H}, \mathrm{s}), 6.97-6.87(2 \mathrm{H}, \mathrm{m}), 6.84(1 \mathrm{H}, \mathrm{d}, J=7.9 \mathrm{~Hz}), 6.58-6.49$ $(1 \mathrm{H}, \mathrm{m}), 6.18(1 \mathrm{H}, \mathrm{s}), 3.95(2 \mathrm{H}, \mathrm{t}, J=5.5 \mathrm{~Hz}), 3.48(2 \mathrm{H}, \mathrm{t}$, $J=5.5 \mathrm{~Hz}), 2.58(3 \mathrm{H}, \mathrm{s}), 2.32(1 \mathrm{H}, \mathrm{tt}, J=7.1,3.7 \mathrm{~Hz}), 2.26(3 \mathrm{H}$, s), 0.75-0.67 (2H, m), 0.45-0.37 (2H, m). ${ }^{13} \mathrm{C}-\mathrm{NMR}(126 \mathrm{MHz}$, $\left.\mathrm{CDCl}_{3}\right) \delta: 166.52,159.63,154.87,148.87,139.77,132.62$, $132.29,131.04,126.27,125.62,122.84,122.30,120.58,115.94$, $113.13,111.57,48.86,41.48,31.07,20.10,19.28,7.92$. IR (KBr) $\mathrm{cm}^{-1}: 1630.98,1414.40,1328.77,1085.80,741.82$. HPLC-MS: $6.89 \mathrm{~min}, 474.2\left(\mathrm{M}+\mathrm{H}^{+}\right)$. HR-MS (ESI): $m / z\left(\mathrm{M}+\mathrm{H}^{+}\right)$Calcd for $\mathrm{C}_{23} \mathrm{H}_{22} \mathrm{O}_{2} \mathrm{~N}_{3} \mathrm{Cl}_{2} \mathrm{~S}$ : 474.0804. Found: 474.0800 .

(4-Cyclopropyl-3,4-dihydroquinoxalin-1(2H)-yl)(4-(2,5- 
dichloro-4-hydroxyphenoxy)-2-methylthiazol-5-yl)methanone (31d) A flask was charged with 30n (85 mg, 0.16 mmol), $\mathrm{PdCl}_{2}$ (dppf) $\cdot \mathrm{CH}_{2} \mathrm{Cl}_{2} \quad(26 \mathrm{mg}, \quad 0.032 \mathrm{mmol}), \quad$ bis(pinacolato)diboron $(60 \mathrm{mg}, 0.24 \mathrm{mmol})$ and $\mathrm{KAc}(31 \mathrm{mg}, 0.31 \mathrm{mmol})$ in 1,4-dioxane under an atmosphere of nitrogen, and then heat at $130^{\circ} \mathrm{C}$ for $3 \mathrm{~h}$. After completion, the resulting mixture was cooled to r.t. and filtered to remove the suspended solids. The filtrate was concentrated to dryness to give a crude intermediate and that was carried forward crude into the next step. The crude intermediate was redissolved in THF, then cooled to $0^{\circ} \mathrm{C}$ and $\mathrm{H}_{2} \mathrm{O}_{2}(357 \mu \mathrm{L}, 3.15 \mathrm{mmol})$ was added dropwise. After the addition was completed, the reaction mixture was warmed to r.t. and stirring was continued for $3 \mathrm{~h}$. Upon completion, the reaction was quenched with saturated aqueous $\mathrm{Na}_{2} \mathrm{SO}_{3}$ and extracted with EtOAc three times. The combined organic phases were washed with brine, dried over $\mathrm{MgSO}_{4}$, filtered and evaporated under reduced pressure. The residue was purified by flash column chromatography to obtain the title compound 31b $(45 \mathrm{mg})$ as a light yellow solid in $60 \%$ yield. $\mathrm{mp}$ $187^{\circ} \mathrm{C} .{ }^{1} \mathrm{H}-\mathrm{NMR}\left(400 \mathrm{MHz}, \mathrm{CDCl}_{3}\right) \delta$ : $7.00-6.89(3 \mathrm{H}, \mathrm{m}), 6.84$ $(1 \mathrm{H}, \mathrm{d}, J=7.9 \mathrm{~Hz}), 6.54(1 \mathrm{H}, \mathrm{d} \mathrm{dd}, J=8.4,6.8,1.9 \mathrm{~Hz}), 6.11(1 \mathrm{H}$, s), $5.93(1 \mathrm{H}, \mathrm{s}), 3.95(2 \mathrm{H}, \mathrm{t}, J=5.5 \mathrm{~Hz}), 3.48(2 \mathrm{H}, \mathrm{t}, J=5.5 \mathrm{~Hz})$, $2.59(3 \mathrm{H}, \mathrm{s}), 2.32(1 \mathrm{H}, \mathrm{tt}, J=6.8,3.7 \mathrm{~Hz}), 0.76-0.67(2 \mathrm{H}, \mathrm{m})$, 0.44-0.37 (2H, m). ${ }^{13} \mathrm{C}-\mathrm{NMR}\left(126 \mathrm{MHz}, \mathrm{CDCl}_{3}\right) \delta: 167.01$, $159.65,155.37,148.68,143.87,139.98,126.35,125.80,123.94$, $122.81,120.94,118.61,117.07,115.93,113.25,110.64,48.89$, 41.57, 31.01, 19.90, 7.95. HPLC-MS: $5.28 \mathrm{~min}, 476.1\left(\mathrm{M}+\mathrm{H}^{+}\right)$. HR-MS (ESI): $m / z \quad\left(\mathrm{M}+\mathrm{H}^{+}\right)$Calcd for $\mathrm{C}_{22} \mathrm{H}_{20} \mathrm{O}_{3} \mathrm{~N}_{3} \mathrm{Cl}_{2} \mathrm{~S}$ : 476.0597. Found: 476.0601.

4-(5-Chloro-2-nitrophenoxy)-2-methylthiazole-5-carboxylic Acid The carboxylic acid intermediate shown above was synthesized from 27a with the method described that preparation of $\mathbf{1 7 a}$ from 16a in yield of $93 \%$. ${ }^{1} \mathrm{H}-\mathrm{NMR}$ (300 MHz, DMSO) $\delta: 10.28(1 \mathrm{H}, \mathrm{br}), 7.91(1 \mathrm{H}, \mathrm{d}, J=7.2 \mathrm{~Hz})$, $7.15(1 \mathrm{H}, \mathrm{d}, J=1.2 \mathrm{~Hz}), 7.02(1 \mathrm{H}, \mathrm{dd}, J=1.2,7.2 \mathrm{~Hz}), 2.54(3 \mathrm{H}$, s).

(4-(5-Chloro-2-nitrophenoxy)-2-methylthiazol-5-yl)(4cyclopropyl-3,4-dihydroquinoxalin-1(2H)-yl)methanone (32a) The title compound 32a was obtained as a yellow solid from the intermediates shown above according to the general procedure that preparation of $13 \mathrm{c}$ from $12 \mathrm{c} . \mathrm{mp} 159^{\circ} \mathrm{C}$. ${ }^{1} \mathrm{H}-\mathrm{NMR}\left(300 \mathrm{MHz}, \mathrm{CDCl}_{3}\right) \delta: 7.83(1 \mathrm{H}, \mathrm{d}, J=8.7 \mathrm{~Hz}), 7.10$ $(1 \mathrm{H}, \mathrm{dd}, J=2.1,8.7 \mathrm{~Hz}), 6.93-6.81(3 \mathrm{H}, \mathrm{m}), 6.55-6.50(1 \mathrm{H}, \mathrm{m})$, $6.29(1 \mathrm{H}, \mathrm{s}), 3.93(2 \mathrm{H}, \mathrm{t}, J=5.4 \mathrm{~Hz}), 3.48(2 \mathrm{H}, \mathrm{t}, J=5.4 \mathrm{~Hz})$, $2.59(3 \mathrm{H}, \mathrm{s}), 2.28(1 \mathrm{H}, \mathrm{m}), 0.71(2 \mathrm{H}, \mathrm{m}), 0.38(2 \mathrm{H}, \mathrm{m})$. ${ }^{13} \mathrm{C}-\mathrm{NMR}\left(126 \mathrm{MHz}, \mathrm{CDCl}_{3}\right) \delta: 166.92,158.86,153.11,148.47$, $139.76,139.71,138.51,126.38,126.06,125.27,124.06,122.91$, $121.36,115.91,113.47,113.00,48.81,41.13,31.16,20.05,7.95$. IR $(\mathrm{KBr}) \mathrm{cm}^{-1}: 1629.14,1600.68,1528.36,1503.64,1410.83$, 1331.04, 1229.17, 756.33. HPLC-MS: $6.02 \mathrm{~min}, 471.2\left(\mathrm{M}+\mathrm{H}^{+}\right)$. HR-MS (ESI): $m / z \quad\left(\mathrm{M}+\mathrm{H}^{+}\right)$Calcd for $\mathrm{C}_{22} \mathrm{H}_{20} \mathrm{O}_{4} \mathrm{~N}_{4} \mathrm{ClS}$ : 471.0888. Found: 471.0875.

(4-Cyclopropyl-3,4-dihydroquinoxalin-1(2H)-yl)(2-methyl-4-(5-methyl-2-nitrophenoxy)thiazol-5-yl)methanone (32b) The title compound 32b was obtained as a light yellow solid according to the procedure that preparation of the title compound 32a. mp $94^{\circ} \mathrm{C}$. ${ }^{1} \mathrm{H}-\mathrm{NMR}\left(300 \mathrm{MHz}, \mathrm{CDCl}_{3}\right) \delta: 7.81$ $(1 \mathrm{H}, \mathrm{d}, J=6.3 \mathrm{~Hz}), 6.97-6.88(4 \mathrm{H}, \mathrm{m}), 6.54(1 \mathrm{H}, \mathrm{m}), 6.16(1 \mathrm{H}$, s), $3.95(2 \mathrm{H}, \mathrm{t}, J=4.2 \mathrm{~Hz}), 3.47(2 \mathrm{H}, \mathrm{t}, J=4.2 \mathrm{~Hz}), 2.56(3 \mathrm{H}, \mathrm{s})$, $2.28(4 \mathrm{H}, \mathrm{m}), 0.70(2 \mathrm{H}, \mathrm{m}), 0.38(2 \mathrm{H}, \mathrm{m}) .{ }^{13} \mathrm{C}-\mathrm{NMR}(126 \mathrm{MHz}$, $\left.\mathrm{CDCl}_{3}\right) \delta: 166.63,163.28,159.39,154.38,147.97,145.65$,
$139.78,138.10,127.08,125.92,125.21,124.82,123.10,121.75$, $115.86,113.07,48.84,41.70,31.13,21.45,20.03,7.91$. HPLCMS: $5.72 \mathrm{~min}, 451.2\left(\mathrm{M}+\mathrm{H}^{+}\right)$. HR-MS (ESI): $\mathrm{m} / \mathrm{z}\left(\mathrm{M}+\mathrm{H}^{+}\right)$ Calcd for $\mathrm{C}_{23} \mathrm{H}_{23} \mathrm{O}_{4} \mathrm{~N}_{4} \mathrm{~S}$ : 451.1435 . Found: 451.1430 .

(4-Cyclopropyl-3,4-dihydroquinoxalin-1(2H)-yl)(4(2,5-dichlorophenoxy)-2-ethylthiazol-5-yl)methanone (37a) The title compound 37a was obtained as a light yellow solid according to the procedure that preparation of the title compound 30c. $\mathrm{mp} 102^{\circ} \mathrm{C}$. ${ }^{1} \mathrm{H}-\mathrm{NMR}\left(400 \mathrm{MHz}, \mathrm{CDCl}_{3}\right) \delta: 7.20$ $(1 \mathrm{H}, \mathrm{d}, J=8.5 \mathrm{~Hz}), 6.95-6.87(2 \mathrm{H}, \mathrm{m}), 6.87-6.82(1 \mathrm{H}, \mathrm{m})$, $6.79(1 \mathrm{H}, \mathrm{d}, J=7.8 \mathrm{~Hz}), 6.52(1 \mathrm{H}, \mathrm{td}, J=8.1,7.6,1.5 \mathrm{~Hz}), 6.14$ $(1 \mathrm{H}, \mathrm{s}), 3.94(2 \mathrm{H}, \mathrm{t}, J=5.5 \mathrm{~Hz}), 3.49(2 \mathrm{H}, \mathrm{t}, J=5.4 \mathrm{~Hz}), 2.91$ $(2 \mathrm{H}, \mathrm{q}, J=7.5 \mathrm{~Hz}), 2.34-2.27(1 \mathrm{H}, \mathrm{m}), 1.33(3 \mathrm{H}, \mathrm{t}, J=7.6 \mathrm{~Hz})$, 0.75-0.69 (2H, m), 0.46-0.40 (2H, m). ${ }^{13} \mathrm{C}-\mathrm{NMR}(126 \mathrm{MHz}$, $\left.\mathrm{CDCl}_{3}\right) \quad \delta: 173.34,159.55,153.98,150.97,139.63,132.40$, $130.24,126.32,125.33,124.37,122.78,122.23,119.64,115.85$, $113.06,112.40,48.82,41.26,31.12,27.58,13.45,7.91$. IR (KBr) $\mathrm{cm}^{-1}: 1632.63,1475.48,1414.25,1329.43,734.26$. HPLC-MS: $7.33 \mathrm{~min}, 474.1\left(\mathrm{M}+\mathrm{H}^{+}\right)$. HR-MS (ESI): $m / z\left(\mathrm{M}+\mathrm{H}^{+}\right)$Calcd for $\mathrm{C}_{23} \mathrm{H}_{22} \mathrm{O}_{2} \mathrm{~N}_{3} \mathrm{Cl}_{2} \mathrm{~S}$ : 474.0804. Found: 474.0797.

(4-(3-Chlorophenoxy)-2-ethylthiazol-5-yl)(4-cyclopropyl-3,4-dihydroquinoxalin-1(2H)-yl)methanone (37b) The title compound $\mathbf{3 7 b}$ was obtained as a light yellow solid according to the procedure that preparation of the title compound 30i. mp $84^{\circ} \mathrm{C}$. ${ }^{1} \mathrm{H}-\mathrm{NMR}\left(400 \mathrm{MHz}, \mathrm{CDCl}_{3}\right) \delta: 7.10$ $(1 \mathrm{H}, \mathrm{t}, J=8.1 \mathrm{~Hz}), 7.02-6.93(3 \mathrm{H}, \mathrm{m}), 6.81(1 \mathrm{H}, \mathrm{d}, J=8.0 \mathrm{~Hz})$, 6.55-6.47 (3H, m), $3.92(2 \mathrm{H}, \mathrm{t}, J=5.6 \mathrm{~Hz}), 3.37(2 \mathrm{H}, \mathrm{t}$, $J=5.6 \mathrm{~Hz}), 2.91(2 \mathrm{H}, \mathrm{q}, J=7.5 \mathrm{~Hz}), 2.35-2.28(1 \mathrm{H}, \mathrm{m}), 1.33(3 \mathrm{H}$, t, $J=7.6 \mathrm{~Hz}), 0.78-0.72(2 \mathrm{H}, \mathrm{m}), 0.47-0.41(2 \mathrm{H}, \mathrm{m}) .{ }^{13} \mathrm{C}-\mathrm{NMR}$ $\left(126 \mathrm{MHz}, \mathrm{CDCl}_{3}\right) \delta: 173.23,159.77,155.85,154.73,139.87$, $134.35,129.78,126.18,125.81,123.69,122.67,118.47,116.33$, $116.06,113.20,112.24,48.94,41.55,31.19,29.70,27.58,13.47$, 7.94. HPLC-MS: $7.02 \mathrm{~min}, 440.2\left(\mathrm{M}+\mathrm{H}^{+}\right)$. HR-MS (ESI): $\mathrm{m} / \mathrm{z}$ $\left(\mathrm{M}+\mathrm{H}^{+}\right)$Calcd for $\mathrm{C}_{23} \mathrm{H}_{23} \mathrm{O}_{2} \mathrm{~N}_{3} \mathrm{ClS}: 440.1194$. Found: 440.1188 .

(4-Cyclopropyl-3,4-dihydroquinoxalin-1(2H)-yl)(4-(2,5dichlorophenoxy)-2-isopropylthiazol-5-yl)methanone (37c) The title compound 37c was obtained as a light yellow solid according to the procedure that preparation of the title compound 30c. mp $89^{\circ} \mathrm{C} .{ }^{1} \mathrm{H}-\mathrm{NMR}\left(400 \mathrm{MHz}, \mathrm{CDCl}_{3}\right) \delta: 7.20(1 \mathrm{H}$, $\mathrm{d}, J=8.5 \mathrm{~Hz}), 6.92(1 \mathrm{H}, \mathrm{dd}, J=8.5,2.3 \mathrm{~Hz}), 6.90-6.82(2 \mathrm{H}, \mathrm{m})$, $6.79(1 \mathrm{H}, \mathrm{d}, J=7.8 \mathrm{~Hz}), 6.51(1 \mathrm{H}, \mathrm{ddd}, J=8.1,7.0,1.8 \mathrm{~Hz}), 6.17$ $(1 \mathrm{H}, \mathrm{s}), 3.95(2 \mathrm{H}, \mathrm{t}, J=5.4 \mathrm{~Hz}), 3.49(2 \mathrm{H}, \mathrm{t}, J=5.5 \mathrm{~Hz}), 3.17$ $(1 \mathrm{H}, \mathrm{p}, J=6.9 \mathrm{~Hz}), 2.34-2.27(1 \mathrm{H}, \mathrm{m}), 1.33(6 \mathrm{H}, \mathrm{d}, J=6.9 \mathrm{~Hz})$, $0.76-0.68(2 \mathrm{H}, \mathrm{m}), 0.48-0.43(2 \mathrm{H}, \mathrm{m}) .{ }^{13} \mathrm{C}-\mathrm{NMR}(126 \mathrm{MHz}$, $\left.\mathrm{CDCl}_{3}\right) \quad \delta: 178.20,159.69,153.79,151.00,139.58,132.34$, $130.22,126.26,125.26,124.21,122.76,122.14,119.51,115.84$, $113.05,112.15,48.79,41.32,33.82,31.16,29.70,22.49,14.13$, 7.93. HPLC-MS: $7.74 \mathrm{~min}, 488.2\left(\mathrm{M}+\mathrm{H}^{+}\right)$. HR-MS (ESI): $m / z\left(\mathrm{M}+\mathrm{H}^{+}\right)$Calcd for $\mathrm{C}_{24} \mathrm{H}_{24} \mathrm{O}_{2} \mathrm{~N}_{3} \mathrm{Cl}_{2} \mathrm{~S}$ : 488.0961. Found: 488.0951 .

(4-(3-Chlorophenoxy)-2-isopropylthiazol-5-yl)(4-cyclopropyl-3,4-dihydroquinoxalin-1(2H)-yl)methanone (37d) The title compound $\mathbf{3 7 d}$ was obtained as a light yellow solid according to the procedure that preparation of the title compound 30i. $\mathrm{mp} 81^{\circ} \mathrm{C}$. ${ }^{1} \mathrm{H}-\mathrm{NMR}\left(400 \mathrm{MHz}, \mathrm{CDCl}_{3}\right) \delta: 7.12-7.06$ $(1 \mathrm{H}, \mathrm{m}), 7.02-6.92(3 \mathrm{H}, \mathrm{m}), 6.81(1 \mathrm{H}, \mathrm{d}, J=7.8 \mathrm{~Hz}), 6.55-6.49$ $(3 \mathrm{H}, \mathrm{m}), 3.92(2 \mathrm{H}, \mathrm{t}, J=5.6 \mathrm{~Hz}), 3.36(2 \mathrm{H}, \mathrm{t}, J=5.5 \mathrm{~Hz}), 3.17$ $(1 \mathrm{H}, \mathrm{p}, J=6.9 \mathrm{~Hz}), 2.35-2.28(1 \mathrm{H}, \mathrm{m}), 1.34(6 \mathrm{H}, \mathrm{d}, J=6.9 \mathrm{~Hz})$, 0.79-0.72 (2H, m), 0.49-0.44 (2H, m). ${ }^{13} \mathrm{C}-\mathrm{NMR}(126 \mathrm{MHz}$, $\left.\mathrm{CDCl}_{3}\right) \quad \delta: 178.12,159.89,155.93,154.48,139.81,134.30$, $129.73,126.14,125.73,123.52,122.63,118.33,116.34,115.86$, 
113.19, 112.14, 48.90, 41.64, 33.82, 31.24, 29.70, 22.50, 7.95. HPLC-MS: $7.42 \mathrm{~min}, \quad 454.2\left(\mathrm{M}+\mathrm{H}^{+}\right)$. HR-MS (ESI): $\mathrm{m} / \mathrm{z}$ $\left(\mathrm{M}+\mathrm{H}^{+}\right)$Calcd for $\mathrm{C}_{24} \mathrm{H}_{25} \mathrm{O}_{2} \mathrm{~N}_{3} \mathrm{ClS}$ : 454.1351. Found: 454.1349 .

(4-Cyclopropyl-3,4-dihydroquinoxalin-1(2H)-yl)(4-(2,5dichlorophenoxy)-2-phenylthiazol-5-yl)methanone

(37e) The title compound 37e was obtained as a yellow solid according to the procedure that preparation of the title compound 30c. $\mathrm{mp} 136^{\circ} \mathrm{C}$. ${ }^{1} \mathrm{H}-\mathrm{NMR}\left(400 \mathrm{MHz}, \mathrm{CDCl}_{3}\right) \delta$ : $7.84-7.78(2 \mathrm{H}$, m), 7.47-7.37 (3H, m), $7.24(1 \mathrm{H}, \mathrm{d}, J=8.6 \mathrm{~Hz}), 6.99-6.81(4 \mathrm{H}$, m), 6.55-6.47 $(1 \mathrm{H}, \mathrm{m}), 6.27(1 \mathrm{H}, \mathrm{s}), 3.98(2 \mathrm{H}, \mathrm{t}, J=5.5 \mathrm{~Hz})$, $3.52(2 \mathrm{H}, \mathrm{t}, J=5.5 \mathrm{~Hz}), 2.36-2.29(1 \mathrm{H}, \mathrm{m}), 0.77-0.69(2 \mathrm{H}, \mathrm{m})$, 0.49-0.42 (2H, m). ${ }^{13} \mathrm{C}-\mathrm{NMR}\left(126 \mathrm{MHz}, \mathrm{CDCl}_{3}\right) \delta: 166.87$, $159.42,155.20,150.94,139.69,132.54,132.37,131.11,130.22$, $129.01,126.41,126.17,125.38,124.55,122.73,122.53,120.07$, $115.97,113.10,112.96,48.82,41.25,31.14,7.95$. IR $(\mathrm{KBr})$ $\mathrm{cm}^{-1}: 1639.69,1472.36,1407.45,1336.07,731.61$. HPLC-MS: $8.15 \mathrm{~min}, 522.2\left(\mathrm{M}+\mathrm{H}^{+}\right)$. HR-MS (ESI): $m / z\left(\mathrm{M}+\mathrm{H}^{+}\right)$Calcd for $\mathrm{C}_{27} \mathrm{H}_{22} \mathrm{O}_{2} \mathrm{~N}_{3} \mathrm{Cl}_{2} \mathrm{~S}$ : 522.0804. Found: 522.0800 .

(4-(3-Chlorophenoxy)-2-phenylthiazol-5-yl)(4-cyclopropyl-3,4-dihydroquinoxalin-1(2H)-yl)methanone

The title compound $\mathbf{3 7 f}$ was obtained as a yellow solid according to the procedure that preparation of the title compound 30i. mp $123^{\circ} \mathrm{C}$. ${ }^{1} \mathrm{H}-\mathrm{NMR}\left(400 \mathrm{MHz}, \mathrm{CDCl}_{3}\right) \delta$ : 7.87-7.80 $(2 \mathrm{H}$, m), 7.47-7.36 $(3 \mathrm{H}, \mathrm{m}), 7.12(1 \mathrm{H}, \mathrm{t}, J=7.9 \mathrm{~Hz}), 7.06-6.93(3 \mathrm{H}$, m), $6.86(1 \mathrm{H}, \mathrm{d}, J=7.9 \mathrm{~Hz}), 6.59(2 \mathrm{H}, \mathrm{d}, J=8.4 \mathrm{~Hz}), 6.56-6.48$ $(1 \mathrm{H}, \mathrm{m}), 3.97-3.94(2 \mathrm{H}, \mathrm{m}), 3.40(2 \mathrm{H}, \mathrm{t}, J=5.6 \mathrm{~Hz}), 2.38-2.30$ $(1 \mathrm{H}, \mathrm{m}), 0.81-0.71$ (2H, m), 0.51-0.43 (2H, m). ${ }^{13} \mathrm{C}-\mathrm{NMR}$ $\left(126 \mathrm{MHz}, \mathrm{CDCl}_{3}\right) \delta: 166.81,159.60,155.85,155.77,139.92$, $134.29,132.61,131.04,129.72,128.98,126.28,126.13,125.85$, $123.80,122.58,118.75,116.44,116.33,113.24,112.95,48.94$, 41.57, 31.22, 7.97. HPLC-MS: $7.05 \mathrm{~min}, 488.2\left(\mathrm{M}+\mathrm{H}^{+}\right)$. HR-MS (ESI): $m / z \quad\left(\mathrm{M}+\mathrm{H}^{+}\right)$Calcd for $\mathrm{C}_{27} \mathrm{H}_{23} \mathrm{O}_{2} \mathrm{~N}_{3} \mathrm{ClS}$ : 488.1194. Found: 488.1186.

(4-Cyclopropyl-3,4-dihydroquinoxalin-1(2H)-yl)(4-(2,5dichlorophenoxy)-2-(pyridin-2-yl)thiazol-5-yl)methanone (37g) The title compound $\mathbf{3 7 g}$ was obtained as a yellow solid according to the procedure that preparation of the title compound 30c. mp $169^{\circ} \mathrm{C}$. ${ }^{1} \mathrm{H}-\mathrm{NMR}\left(400 \mathrm{MHz}, \mathrm{CDCl}_{3}\right) \delta$ : $8.60(1 \mathrm{H}, \mathrm{d}, J=5.0 \mathrm{~Hz}), 7.90(1 \mathrm{H}, \mathrm{d}, J=7.9 \mathrm{~Hz}), 7.72(1 \mathrm{H}, \mathrm{t}$, $J=7.9 \mathrm{~Hz}), 7.40-7.18(2 \mathrm{H}, \mathrm{m}), 7.03-6.77(4 \mathrm{H}, \mathrm{m}), 6.49(1 \mathrm{H}, \mathrm{t}$, $J=7.5 \mathrm{~Hz}), 6.21(1 \mathrm{H}, \mathrm{s}), 3.98(2 \mathrm{H}, \mathrm{d}, J=5.7 \mathrm{~Hz}), 3.52(2 \mathrm{H}, \mathrm{t}$, $J=5.4 \mathrm{~Hz}), 2.32(1 \mathrm{H}, \mathrm{s}), 0.73(2 \mathrm{H}, \mathrm{d}, J=6.5 \mathrm{~Hz}), 0.44(2 \mathrm{H}, \mathrm{s})$. ${ }^{13} \mathrm{C}-\mathrm{NMR}\left(126 \mathrm{MHz}, \mathrm{CDCl}_{3}\right) \delta: 167.27,159.52,155.16,150.98$, $150.06,149.55,139.70,137.05,132.38,130.24,126.46,125.31$, $125.24,124.48,122.88,122.46,119.88,119.79,115.91,115.72$, $113.09,48.81,41.13,31.12,7.93$. IR (KBr) $\mathrm{cm}^{-1}: 1627.25$, $1471.82, \quad 1398.62,1230.21,1075.35,738.43$. HPLC-MS: $7.44 \mathrm{~min}, 523.2\left(\mathrm{M}+\mathrm{H}^{+}\right)$. HR-MS (ESI): $\mathrm{m} / \mathrm{z}\left(\mathrm{M}+\mathrm{H}^{+}\right)$Calcd for $\mathrm{C}_{26} \mathrm{H}_{21} \mathrm{O}_{2} \mathrm{~N}_{4} \mathrm{Cl}_{2} \mathrm{~S}$ : 523.0757. Found: 523.0747.

(4-(3-Chlorophenoxy)-2-(pyridin-2-yl)thiazol-5-yl)(4cyclopropyl-3,4-dihydroquinoxalin-1(2H)-yl)methanone (37h) The title compound $\mathbf{3 7 h}$ was obtained as a yellow solid according to the procedure that preparation of the title compound 30i. mp $142^{\circ} \mathrm{C}$. ${ }^{1} \mathrm{H}-\mathrm{NMR}\left(400 \mathrm{MHz}, \mathrm{CDCl}_{3}\right) \delta: 8.60$ $(1 \mathrm{H}, \mathrm{dt}, J=4.8,1.3 \mathrm{~Hz}), 7.95-7.91(1 \mathrm{H}, \mathrm{m}), 7.72(1 \mathrm{H}, \mathrm{td}, J=7.8$, $1.8 \mathrm{~Hz}), 7.36-7.30(1 \mathrm{H}, \mathrm{m}), 7.13(1 \mathrm{H}, \mathrm{t}, J=8.0 \mathrm{~Hz}), 7.05-6.93$ $(3 \mathrm{H}, \mathrm{m}), 6.83(1 \mathrm{H}, \mathrm{d}, J=7.9 \mathrm{~Hz}), 6.58(2 \mathrm{H}, \mathrm{d}, J=10.2 \mathrm{~Hz}), 6.50$ $(1 \mathrm{H}, \mathrm{td}, J=8.0,7.3,1.9 \mathrm{~Hz}), 3.96(2 \mathrm{H}, \mathrm{t}, J=5.6 \mathrm{~Hz}), 3.40(2 \mathrm{H}$, t, $J=5.6 \mathrm{~Hz}), 2.38-2.30(1 \mathrm{H}, \mathrm{m}), 0.79-0.72(2 \mathrm{H}, \mathrm{m}), 0.49-0.42$ $(2 \mathrm{H}, \mathrm{m}) .{ }^{13} \mathrm{C}-\mathrm{NMR} \quad\left(126 \mathrm{MHz}, \mathrm{CDCl}_{3}\right) \quad \delta: 167.18,159.72$, $155.86,150.16,149.55,139.93,137.04,134.34,130.01,129.77$,
$126.33,125.70,125.25,123.78,122.75,119.75,118.67,116.37$, 116.23, 115.68, 113.23, 48.92, 41.45, 31.21, 7.95. HPLC-MS: $7.26 \mathrm{~min}, 489.2\left(\mathrm{M}+\mathrm{H}^{+}\right)$. HR-MS (ESI): $m / z\left(\mathrm{M}+\mathrm{H}^{+}\right)$Calcd for $\mathrm{C}_{26} \mathrm{H}_{22} \mathrm{O}_{2} \mathrm{~N}_{4}$ ClS: 489.1147 . Found: 489.1137.

Acknowledgments This work was financially supported by Grant from "National Science and Technology Major Project-Key New Drug Creation and Manufacturing program, China" (2012ZX09103101-049) and National Nature Science Foundation of China (Grant 81202571).

Conflict of Interest The authors declare no conflict of interest.

\section{References}

1) Vassileva G., Golovko A., Markowitz L., Abbondanzo S. J., Zeng M., Yang S., Hoos L., Tetzloff G., Levitan D., Murgolo N. J., Keane K., Davis H. R. Jr., Hedrick J., Gustafson E. L., Biochem. J., 398 423-430 (2006)

2) Tiwari A., Maiti P., Drug Discov. Today, 14, 523-530 (2009).

3) Keitel V., Gorg B., Bidmon H. J., Zemtsova I., Spomer L., Zilles K., Haussinger D., Glia, 58, 1794-1805 (2010).

4) Duboc H., Tache Y., Hofmann A. F., Dig. Liver Dis., 46, 302-312 (2014)

5) Watanabe M., Houten S. M., Mataki C., Christoffolete M. A., Kim B. W., Sato H., Messaddeq N., Harney J. W., Ezaki O., Kodama T., Schoonjans K., Bianco A. C., Auwerx J., Nature (London), 439, 484-489 (2006).

6) Katsuma S., Hirasawa A., Tsujimoto G., Biochem. Biophys. Res. Commun., 329, 386-390 (2005).

7) Holst J. J., Physiol. Rev., 87, 1409-1439 (2007).

8) Fineman M. S., Cirincione B. B., Maggs D., Diamant M., Diabetes Obes. Metab., 14, 675-688 (2012).

9) Knop F. K., Am. J. Physiol. Endocrinol. Metab., 299, E10-E13 (2010).

10) Kawamata Y., Fujii R., Hosoya M., Harada M., Yoshida H., Miwa M., Fukusumi S., Habata Y., Itoh F., Shintani Y., Hinuma S., Fujisawa Y., Fujino M., J. Biol. Chem., 278, 9435-9440 (2003).

11) Pellicciari R., Gioiello A., Macchiarulo A., Thomas C., Rosatelli E., Natalini B., Sardella R., Pruzanski M., Roda A., Pastorini E., Schoonjans K., Auwerx J., J. Med. Chem., 52, 7958-7961 (2009).

12) Iguchi Y., Nishimaki-Mogami T., Yamaguchi M., Teraoka F. Kaneko T., Une M., Biol. Pharm. Bull., 34, 1-7 (2011).

13) Sato H., Genet C., Strehle A., Thomas C., Lobstein A., Wagner A., Mioskowski C., Auwerx J., Saladin R., Biochem. Biophys. Res. Commun., 362, 793-798 (2007).

14) Genet C., Strehle A., Schmidt C., Boudjelal G., Lobstein A. Schoonjans K., Souchet M., Auwerx J., Saladin R., Wagner A., $J$. Med. Chem., 53, 178-190 (2010).

15) Ito F., Tawaraishi T., Hirohashi M., Matsumoto H., JP2006056881-A (2006).

16) Dehmlow H., Alvarez Sanchez R., Bachmann S., Bissantz C., Bliss F., Conde-Knape K., Graf M., Martin R. E., Obst Sander U., Raab S., Richter H. G., Sewing S., Sprecher U., Ullmer C., Mattei P., Bioorg. Med. Chem. Lett., 23, 4627-4632 (2013).

17) Evans K. A., Budzik B. W., Ross S. A., Wisnoski D. D., Jin J., Rivero R. A., Vimal M., Szewczyk G. R., Jayawickreme C., Moncol D. L., Rimele T. J., Armour S. L., Weaver S. P., Griffin R. J., Tadepalli S. M., Jeune M. R., Shearer T. W., Chen Z. B., Chen L., Anderson D. L., Becherer J. D., De Los Frailes M., Colilla F. J., J. Med. Chem., 52, 7962-7965 (2009).

18) Piotrowski D. W., Futatsugi K., Warmus J. S., Orr S. T., FreemanCook K. D., Londregan A. T., Wei L., Jennings S. M., Herr M., Coffey S. B., Jiao W., Storer G., Hepworth D., Wang J., Lavergne S. Y., Chin J. E., Hadcock J. R., Brenner M. B., Wolford A. C., 
Janssen A. M., Roush N. S., Buxton J., Hinchey T., Kalgutkar A. S., Sharma R., Flynn D. A., ACS Med. Chem. Lett., 4, 63-68 (2013).

19) Budzik B. W., Evans K. A., Wisnoski D. D., Jin J., Rivero R. A., Szewczyk G. R., Jayawickreme C., Moncol D. L., Yu H., Bioorg. Med. Chem. Lett., 20, 1363-1367 (2010).

20) Futatsugi K., Bahnck K. B., Brenner M. B., Buxton J., Chin J. E., Coffey S. B., Dubins J., Flynn D., Gautreau D., Guzman-Perez A., Hadcock J. R., Hepworth D., Herr M., Hinchey T., Janssen A. M., Jennings S. M., Jiao W., Lavergne S. Y., Li B., Li M., Munchhof M. J., Orr S. T. M., Piotrowski D. W., Roush N. S., Sammons M., Stevens B. D., Storer G., Wang J., Warmus J. S., Wei L., Wolford A. C., MedChem Comm, 4, 205-210 (2013).

21) Londregan A. T., Piotrowski D. W., Futatsugi K., Warmus J. S., Boehm M., Carpino P. A., Chin J. E., Janssen A. M., Roush N. S., Buxton J., Hinchey T., Bioorg. Med. Chem. Lett., 23, 1407-1411 (2013).

22) Duan H., Ning M., Chen X., Zou Q., Zhang L., Feng Y., Zhang L., Leng Y., Shen J., J. Med. Chem., 55, 10475-10489 (2012).

23) Li T., Holmstrom S. R., Kir S., Umetani M., Schmidt D. R., Kliewer
S. A., Mangelsdorf D. J., Mol. Endocrinol., 25, 1066-1071 (2011).

24) Zou Q., Duan H., Ning M., Liu J., Feng Y., Zhang L., Zhu J., Leng Y., Shen J., Eur. J. Med. Chem., 82, 1-15 (2014).

25) Martin R. E., Bissantz C., Gavelle O., Kuratli C., Dehmlow H., Richter H. G., Obst Sander U., Erickson S. D., Kim K., PietranicoCole S. L., Alvarez-Sanchez R., Ullmer C., ChemMedChem, 8, 569-576 (2013).

26) Cottrell I. F., Hands D., Houghton P. G., Humphrey G. R., Wright S. H. B., J. Heterocycl. Chem., 28, 301-304 (1991).

27) Buckle D. R., Rockell C. J. M., J. Chem. Soc., 627-630 (1982)

28) Baasner B., Schwamborn M., Santel H. J., Lurssen K., Schmidt R., US5057142-A (1991).

29) Herbert J. M., Tetrahedron Lett., 45, 817-819 (2004).

30) Zhu J., Ning M., Guo C., Zhang L., Pan G., Leng Y., Shen J., Eur. J. Med. Chem., 69, 55-68 (2013).

31) Zhu J., Ye Y., Ning M., Mandi A., Feng Y., Zou Q., Kurtan T., Leng Y., Shen J., ChemMedChem, 8, 1210-1223 (2013).

32) Duan H., Ning M., Zou Q., Ye Y., Feng Y., Zhang L., Leng Y., Shen J., J. Med. Chem., 58, 3315-3328 (2015). 